\title{
Activating transcription factor 3 inhibits endometrial carcinoma aggressiveness via JunB suppression
}

\author{
FANGYUAN WANG ${ }^{1}$, JINGJING $\mathrm{LI}^{2}$, HAIXIA WANG ${ }^{3}$, FAN ZHANG $^{4}$ and JIN GAO ${ }^{2,4}$ \\ ${ }^{1}$ Shanghai Institute of Rheumatology, Renji Hospital, School of Medicine, Shanghai Jiao Tong University, \\ Shanghai 200127; ${ }^{2}$ School of Pharmacy; ${ }^{3}$ School of Agriculture and Biology, Shanghai Jiao Tong University, \\ Shanghai 200240, P.R. China; ${ }^{4}$ Department of Pharmaceutical Sciences, College of Pharmacy and \\ Pharmaceutical Sciences, Washington State University, Spokane, WA 99202, USA
}

Received February 2, 2020; Accepted May 29, 2020

DOI: $10.3892 /$ ijo.2020.5084

\begin{abstract}
The function of activating transcription factor 3 (ATF3) in cancer is context-dependent and its role in endometrial carcinoma (EC) is yet to be elucidated. In the present study, ATF3 was indicated to be downregulated, while one of the ATF3-interacting proteins, JunB, was upregulated in ECs according to western blot analysis. After overexpression in ECs, ATF3 inhibited the proliferation and invasion of EC cells and enhanced apoptosis, as well as suppressed the expression of JunB. The properties of EC cells, including the expression of matrix metalloproteinases, tissue inhibitors of metalloproteinases, the cell cycle and apoptosis were all altered by overexpression of ATF3. Furthermore, luciferase activity assay, chromatin precipitation and DNA affinity assay results indicated that ATF3 exerted the aforementioned functions via JunB binding and activator protein-1 signaling. However, the interaction between ATF3 and JunB did not occur in EC cells under basal conditions, but in ATF3-overexpressing ECs, which was capable of mitigating EC proliferation, invasion and metastasis. Collectively, the present results suggested that the ATF3/JunB interaction may serve as a potential therapeutic target for ECs.
\end{abstract}

\section{Introduction}

Endometrial carcinoma (EC) is one of the most common types of gynecologic malignancy, with an estimated 61,880 diagnosed cases, accounting for $6.94 \%$ of all new female cancer cases and 12,160 mortalities, leading to $4.26 \%$ of all

Correspondence to: Dr Jin Gao or Dr Fan Zhang, Department of Pharmaceutical Sciences, College of Pharmacy and Pharmaceutical Sciences, Washington State University, PBS 322, 402 E Spokane Falls Boulevard, Spokane, WA 99202, USA

E-mail: jin.gao3@wsu.edu

E-mail: fan.zhang4@wsu.edu

Key words: activating transcription factor 3, JunB, activator protein 1 , endometrial cancer, endometrium, interaction mortalities in females in 2019 according to the American Cancer Society (1). With the development of medical technologies, the majority of ECs are diagnosed at the early stage (stage I-II), according to staging standards of the International Federation of Gynecology and Obstetrics, and hysterectomy is the recommended treatment (2). However, $30 \%$ of EC cases are not diagnosed until metastasis is identified (stage III-IV), which is associated with low survival and worse prognosis $(3,4)$. Furthermore, particularly for patients with EC who are nulliparous, hysterectomy is not a primary treatment option (5). Currently, the global incidence of EC is on the rise. In 2013, there were an estimated 49,560 cases in the USA, while by 2018 , the number of new cases had risen to 63,230 individuals (6); this increase may be attributed to an increased prevalence of patients who are overweight, obese and physically inactive $(7,8)$. Therefore, therapeutic strategies focusing on inhibiting the proliferation, migration and invasion of EC are critical to the treatment and prognosis of patients with EC. However, the molecular and cellular mechanisms responsible for the carcinogenesis, progression and survival prognosis of ECs have remained elusive.

EC is classified into two subtypes: Type I, accounting for $85 \%$ of total cases, $20-50 \%$ of which have acquired p53-mutant status; and type II, accounting for $15 \%$ of total cases, $>90 \%$ of which have p53-mutant status (9-11). Previous studies have reported that activating transcription factor 3 (ATF3) binds to the $\mathrm{C}$ terminus of wild-type (WT) p53, preventing p53 from ubiquitin-mediated degradation in response to DNA damage (12). Moreover, ATF3 is able to bind to mutant p53 to inhibit the migration and invasion of p53-mutated cancer cells, suppressing the oncogenic function of mutant p53 proteins (13). Therefore, ATF3 may be a potential therapeutic target for carcinomas closely linked to p53 mutations, including ECs. To the best of our knowledge, the present study was the first to investigate the role of ATF3 in EC. Its implication in cell proliferation, invasion, signaling pathway markers, matrix metalloproteinases (MMPs), tissue inhibitors of metalloproteinases (TIMPs), protein interaction and DNA binding were assessed to identify the regulatory function of ATF3 in ECs and the potential underlying mechanisms. 


\section{Materials and methods}

Ethics statement. The protocol (approval no. 0101N16032) of the present study was approved by the Human Investigation Ethical Committee of Shanghai First People's Hospital Affiliated Shanghai Jiao Tong University (Shanghai, China) and Renji Hospital Affiliated to Shanghai Jiao Tong University School of Medicine (Shanghai, China). The sampling methods in patients were performed in accordance with the Operational Guidelines for Ethics Committees That Review Biomedical Research (https://www.who.int/tdr/publications/documents/ethics.pdf). All samples were obtained from patients who had provided written informed consent for the use of their tissues for the purposes of research after the operation.

The animal experiment was in accordance with the recommendations in the Guidelines for the Care and Use of Laboratory Animals of China (http://www.nsfc.gov. cn/nsfc/cen/pfzl/pufanew/20110801_02.pdf). The protocol (approval no. 2013020346) was approved by the Committee on the Ethics of Animal Experiments of the School of Pharmacy of Shanghai Jiao Tong University (Shanghai, China). All efforts were made to minimize animal suffering.

Cell culture, plasmids and transfections. The human EC cell lines HEC-1B and AN3CA were cultured in DMEM/nutrient mixture F-12 (DMEM/F12; Hyclone; Cytiva) supplemented with $10 \%$ heat-inactivated fetal bovine serum (FBS, Gibco; Thermo Fisher Scientific, Inc.) and 1\% penicillin/streptomycin (Gibco; Thermo Fisher Scientific, Inc.). These cell lines were purchased from the Chinese Academy of Sciences Committee Type Culture Collection and were routinely maintained in the Fangyuan Wang's laboratory. Cell cultures were maintained at $37^{\circ} \mathrm{C}$ in a humidified incubator with $5 \% \mathrm{CO}_{2}$. The plasmid pShuttle Vector containing the open reading frame (ORF) of ATF3 was obtained from GeneCopoeia, Inc.

For transfection, the ATF3 ORF was inserted to the multiple cloning sites of pCMV-script (Agilent Technologies, Inc.) and transfected using Lipofectamine ${ }^{\circledR} 3000$ (Invitrogen; Thermo Fisher Scientific, Inc.). To stably express ATF3 in HEC-1B and AN3CA cells, the EC cells were transfected with pCMV-script-ATF3 or the negative control (NC) vector pCMV-script $(5 \mu \mathrm{g})$ and then selected with G418 $(800 \mu \mathrm{g} / \mathrm{ml}$; Sigma-Aldrich; Merck KGaA) after 6 weeks to obtain the stable transfection cell lines. The cell lines with ATF3 overexpression were referred to as 'HEC-1B-ATF3' and 'AN3CA-ATF3', respectively, with their control cells referred to as 'HEC-1B-NC' and 'AN3CA-NC', respectively.

Tissue collection. EC samples ( $\mathrm{n}=50$; age, 29-67 years) and the healthy samples adjacent to tumor tissues $(n=6$; age, 35-62 years) were obtained from patients who received surgical therapy at the Department of Obstetrics and Gynecology, Shanghai First People's Hospital Affiliated to Shanghai Jiao Tong University (Shanghai, China), between February 2010 and December 2013. The healthy tissues were from the same group of patients for the EC tissues. In brief, a vaginal speculum was used to expose the cervix after general or local anesthesia, followed by disinfection of the cervix using $0.5 \%$ povidone iodine (Qingdao Hainuo Biology Engineering Co., Ltd.) and paralysis of the cervical canal via a multiple-point injection of
1\% lidocaine 20-100 mg (Tianjin Zhongxin Pharmaceutical Group Co., Ltd.). The cervix was then dilated, and the uterine cavity was penetrated using a long and thin metal rod with a curette at the end to perform curettage of the endometrium. Tumor staging and histological grading were performed according to the International Federation for Obstetrics and Gynecology criteria (2009) (14). Clinical and pathological data of the cohort are presented in Table I.

Primary cell culture. Fresh clinical samples of the tumor $(1 \mathrm{~cm})$ were minced into $2-\mathrm{mm}$ fragments and then transferred to a solution of trypsin $0.25 \%$ in medium (containing $0.1 \mathrm{mM}$ EDTA), followed by incubation at $37^{\circ} \mathrm{C}$ for $20 \mathrm{~min}$. Isolated EC cells were recovered in $0.5 \%$ trypsin inhibitor (Merck $\mathrm{KGaA}$ ) and $1.0 \%$ albumin (Sigma-Aldrich; Merck KGaA) in DMEM/F12 medium and then isolated by centrifugation at $400 \mathrm{x} \mathrm{g}$ for $10 \mathrm{~min}$ at $4^{\circ} \mathrm{C}$. The cells obtained were manually counted using a hemocytometer under a light microscope (magnification, $x 40$; Eclipse Ts2; Nikon Corporation) and transferred to $75-\mathrm{cm}^{2}$ culture flasks and incubated in medium supplemented with $10 \% \mathrm{FBS}$ in an incubator at $37^{\circ} \mathrm{C}$ with a humidified atmosphere containing $5 \% \mathrm{CO}_{2}$.

Immunohistochemical staining. EC tissues, adjacent healthy tissues or xenografts were fixed using $10 \%$ neutral paraformaldehyde at room temperature for $24 \mathrm{~h}$ and then sections with a thickness of $5 \mu \mathrm{m}$ were prepared. After deparaffinization and dehydration, sections were boiled in $10 \mathrm{mM}$ tris(hydroxymethyl) aminomethane-Ethylenediaminetetraacetic acid (Tris-EDTA) buffer to retrieve antigens and then blocked in 5\% normal goat serum (Sigma-Aldrich; Merck KGaA) at room temperature for $2 \mathrm{~h}$. After incubation with primary antibodies overnight at $4^{\circ} \mathrm{C}$, sections and secondary antibodies at room temperature for $1 \mathrm{~h}$, the sections were stained using an ABC Elite kit (cat. no. PK6200; Vector Laboratories, Inc.) and a diaminobenzidine kit (cat. no. SK4100; Vector Laboratories, Inc.) according to the manufacturer's protocol. The images of sections were captured under a light microscope (magnification, x40; Eclipse Ts2; Nikon Corporation). Primary antibodies used in the present study were rabbit polyclonal anti-ATF3 antibody (cat. no. ab87213; 1:200; Abcam), mouse monoclonal anti-JunB antibody (cat. no. sc8051; 1:200; Santa Cruz Biotechnology, Inc.) anti-proliferating cell nuclear antigen antibody (PCNA; cat. no. ab29; 1:100; Abcam) and rabbit polyclonal anti-Ki67 antibody (cat. no. ab15580; 1:100; Abcam). For the biotinylated horseradish peroxidase anti-rabbit or anti-mouse secondary antibodies were included in the ABC Elite kit, and a dilution of $1: 3,000$ was used.

Reverse transcription-quantitative PCR (RT-qPCR). Total RNA was extracted from HEC-1B-NC, HEC-1B-ATF3, AN3CA-NC and AN3CA-ATF3 cells with TRIzol ${ }^{\circledR}$ reagent (Invitrogen; Thermo Fisher Scientific, Inc.) and reverse transcribed at $42^{\circ} \mathrm{C}$ for $30 \mathrm{~min}$ to cDNA using the Prime Script RT reagent kit (Takara Bio, Inc.). RT-qPCR was performed using SYBR Premix Ex Taq (Takara Bio, Inc.) and analyzed with an ABI Prism 7000 Sequence Detection System (Applied Biosystems; Thermo Fisher Scientific, Inc.). The thermocycling conditions were as follows: Initial denaturation at $95^{\circ} \mathrm{C}$ for $10 \mathrm{~min}$, followed by 42 cycles at $95^{\circ} \mathrm{C}$ for $15 \mathrm{sec}, 60^{\circ} \mathrm{C}$ 
Table I. Clinicopathological summary of the samples from patients with endometrial carcinoma.

\begin{tabular}{lcc}
\hline $\begin{array}{l}\text { Clinical pathological } \\
\text { variables }\end{array}$ & Number & Ratio (\%) \\
\hline Age (years) & & \\
$\geq 55$ & 40 & 80 \\
$<55$ & 10 & 20 \\
FIGO stage & & \\
Stage I & 31 & 62 \\
Stage II & 11 & 22 \\
Stage III & 8 & 16 \\
Grade & & 52 \\
G1 & 26 & 30 \\
G2 & 15 & 18 \\
G3 & 9 & 80 \\
Myometrial invasion & & 20 \\
$<1 / 2$ & 40 & 18 \\
$\geq 1 / 2$ & 10 & 82 \\
Nodal metastasis & & 100 \\
Positive & 9 & \\
Negative & 41 & \\
Total & 50 & \\
\hline
\end{tabular}

FIGO, International Federation of Gynecology and Obstetrics (14).

for $1 \mathrm{~min}$ and $72^{\circ} \mathrm{C}$ for $1.5 \mathrm{~min}$. The oligonucleotide primer sequences used for RT-qPCR were as follows: ATF3 forward, 5'-CATCTTTGCCTCAACTCCAG-3' and reverse, 5'-GAC ACTGCTGCCTGAATCCT-3'; JunB forward, 5'-AGCCAC CTCCCGTTTACA-3' and reverse, 5'-TCTGCGGTTCCT CCTTGA-3'; and GAPDH forward, 5'-AGGTCGGAGTCA ACGGATTTG-3' and reverse, 5'-GTGATGGCATGGACT GTGGT-3'. All the qPCR analyses were performed following the procedures reported previously (15). Values on the $y$-axis equal to $2^{-\Delta \Delta \mathrm{Cq}}$ were selected, where $\Delta \mathrm{Cq}$ is the difference between the target gene $\mathrm{Cq}$ and the normalizer gene $\mathrm{Cq} . \mathrm{Cq}$ represents the cycle of the threshold at which the fluorescence increases above the baseline with statistical significance. Gene expression data were obtained from three independent experiments. With regard to the RT-qPCR analysis of MMPs and TIMPs, the experiment was conducted as aforementioned and all oligos (Table II) were supplied in the RT ${ }^{2}$ qPCR First Strand kit (cat. no. 330404; Qiagen, Inc.).

Western blot (WB) analysis. The primary EC cells, HEC-1B and AN3CA cells were lysed using Extraction and Quantification ProteoJET Mammalian Cell Lysis reagent (Fermentas; Thermo Fisher Scientific, Inc.) with protease inhibitor cocktail (Roche Diagnostics). Total protein concentrations were determined using the bicinchoninic acid (BCA) method (Pierce; Thermo Fisher Scientific, Inc.). A total of $50 \mu \mathrm{g}$ protein was separated by $12 \%$ SDS-PAGE and transferred to a polyvinylidene difluoride membrane. Membranes were blocked using 5\% non-fat milk powder for
$1 \mathrm{~h}$ at room temperature, incubated with primary antibodies overnight at $4^{\circ} \mathrm{C}$ and then washed three times in Tris-buffered saline ( $\mathrm{pH}$ 7.4). Subsequently, membranes were incubated for $2 \mathrm{~h}$ with secondary antibodies at room temperature. The primary antibodies used were as follows: Rabbit anti-ATF3 (1:200; cat. no. ab216569; Abcam), mouse anti-JunB (1:200; cat. no. sc-8051; Santa Cruz Biotechnology, Inc.) and rabbit anti-GAPDH (1:20,000; cat. no. ab199553; Abcam). Secondary horseradish peroxidase-conjugated goat anti-rabbit (1:1,000; cat. no. sc-2004; Santa Cruz Biotechnology, Inc.) and goat anti-mouse antibodies (1:4,000; cat. no. SA00001-1; ProteinTech Group, Inc.) were visualized with the Super Signal West Pico chemiluminescent substrate (Thermo Fisher Scientific, Inc.) using a gel imaging system with a preconfigured Image Lab software 5.2.1 (ChemiDoc XRS ${ }^{+}$; Bio-Rad Laboratories, Inc.).

For the apoptosis marker detection, HEC-1B-NC, HEC-1B-ATF3, AN3CA-NC or AN3CA-ATF3 cells were lysed and the protein concentrations were determined using $\mathrm{BCA}$ assay. The cell lysates were subject to WB analysis as aforementioned using the primary antibodies anti-poly(ADP-ribose) polymerase (PARP; 1:500; cat. no. 614302; Biolegend, Inc.), anti-Bcl2 (1:1,000; cat. no. 658702; Biolegend, Inc.), anti-Bcl-x (1:500; cat. no. 633902; Biolegend, Inc.), anti-Bax (1:200; cat. no. 633602; Biolegend, Inc.), anti-p38 (1:500; cat. no. 622402; Biolegend, Inc.) and anti-phosphorylated (p)-p38 antibodies (1:200; cat. no. 690202; Biolegend, Inc.).

Yeast two-hybrid (Y2H) assay. The $\mathrm{Y} 2 \mathrm{H}$ assay was performed using a Matchmaker Gal4-based two-hybrid assay kit (Clontech Laboratories, Inc.) according to the manufacturer's instructions. A bait protein (ATF3) was expressed in the yeast strain Y2HGold as a fusion to the Gal4 DNA-binding domain (DNA-BD) using the pGBKT7 vector with the ORF of ATF3 inserted, while the prey proteins from the the high-complexity EC library, which are provided in yeast strain Y187, were expressed as fusions to the Gal4 activation domain (AD) using the pGADT7 vector, according to manufacturer's protocols. When cultures of the two transformed strains were mixed together for 20-24 h at $30^{\circ} \mathrm{C}$ with slow shaking at $1-5 \mathrm{x}$ g, they mated to create diploids. Thus, the DNA-BD and AD were guided into proximity to activate the transcription of four independent reporter genes (AUR1-C, ADE2, HIS3 and MEL1, coding for enzyme inositol phosphoryl ceramide synthase, histidine, adenine and $\alpha$-galactosidase, respectively). Via streaking with toothpicks onto high-stringency selective synthetic dropout media supplemented with $20 \mu \mathrm{g} / \mathrm{ml} \mathrm{X}-\alpha-\mathrm{Gal}$, screening was performed based on whether bait (ATF3) and prey (library) fusion proteins interacted with each other. The interactions between the baits and preys were determined $24 \mathrm{~h}$ after culturing at $30^{\circ} \mathrm{C}$. The positive control mating between Y2HGold [pGBKT7-53] and Y187 [pGADT7-T], and the NC mating between Y2HGold [pGBKT7-Lam] and Y187 [pGADT7-T] were performed simultaneously. Autoactivation of reporter genes in Y2HGold by the bait (ATF3) was confirmed via streaking the plasmid-harbored yeast cells on the selective synthetic dropout media prior to the two-hybrid screen, in the absence of a prey protein.

Polyhistidine (His) tag-fused ATF3 (His-ATF3) expression and purification. The ORF of ATF3 was subcloned into the 
Table II. Primer sequences used for quantitation of MMPs and TIMPs.

A, MMPs.

\begin{tabular}{|c|c|c|}
\hline Gene & Direction & Sequences \\
\hline \multirow[t]{2}{*}{ MMP2 } & Forward & 5'-AACTACGATGACGACCGCAAGT-3' \\
\hline & Reverse & 5'-AGGTGTAAATGGGTGCCATCA-3' \\
\hline \multirow[t]{2}{*}{ MMP3 } & Forward & 5'-TTCCGCCTGTCTCAAGATGATAT-3' \\
\hline & Reverse & 5'-AAAGGACAAAGCAGGATCACAGTT-3' \\
\hline \multirow[t]{2}{*}{ MMP7 } & Forward & 5'-CTTTGCGCGAGGAGCTCA-3' \\
\hline & Reverse & 5'-CAGGCGCAAAGGCATGA-3' \\
\hline \multirow[t]{2}{*}{ MMP9 } & Forward & 5'-AGGCGCTCATGTACCCTATGTAC-3' \\
\hline & Reverse & 5'-GCCGTGGCTCAGGTTCA-3' \\
\hline \multirow[t]{2}{*}{ MMP10 } & Forward & 5'-GGACCTGGGCTTTATGGAGATAT-3' \\
\hline & Reverse & 5'-CCCAGGGAGTGGCCAAGT-3' \\
\hline \multirow[t]{2}{*}{ MMP11 } & Forward & 5'-GGGTGCCCTCTGAGTCGA-3' \\
\hline & Reverse & 5'-TCACAGGGTCAAACTTCCAGTAGA-3' \\
\hline \multirow[t]{2}{*}{ MMP13 } & Forward & 5'-AAATTATGGAGGAGATGCCCATT-3' \\
\hline & Reverse & 5'-TCCTTGGAGTGGTCAAGACCTAA-3' \\
\hline
\end{tabular}

B, TIMPs

\begin{tabular}{lll}
\hline Gene & Direction & \multicolumn{1}{c}{ Sequences } \\
\hline TIMP1 & Forward & 5'-GACGGCCTTCTGCAATTCC-3' \\
& Reverse & 5'-GTATAAGGTGGTCTGGTTGACTTCTG-3' \\
TIMP2 & Forward & 5'-GAGCCTGAACCACAGGTACCA-3' \\
& Reverse & 5'-AGGAGATGTAGCACGGGATCA-3' \\
TIMP3 & Forward & 5'-CCAGGACGCCTTCTGCAA-3' \\
& Reverse & 5'-CCCCTCCTTTACCAGCTTCTTC-3' \\
TIMP4 & Forward & 5'-CACCCTCAGCAGCACATCTG-3' \\
& Reverse & 5'-GGCCGGAACTACCTTCTCACT-3'
\end{tabular}

MMP, matrix metalloproteinase; TIMP, tissue inhibitors of metalloproteinase.

pET32a vector (Novagen; Merck KGaA) and introduced into Escherichia coli BL21 (Invitrogen; Thermo Fisher Scientific, Inc.) following the manufacturer's protocol. His-ATF3 was induced in the host bacteria using $0.2 \mu \mathrm{M}$ isopropyl- $\beta$-D-1-t hiogalactopyranoside (IPTG; Sigma-Aldrich; Merck KGaA) at $37^{\circ} \mathrm{C}$ for $4 \mathrm{~h}$ and the soluble protein of His-ATF3 was purified using a His-Tag purification column (Sigma-Aldrich; Merck KGaA) according to the manufacturer's instructions.

BIAcore assay. The affinity and binding kinetics were measured using BIAcore assays. The dissociation rate constant $(\mathrm{Kd})$ between His-ATF3 and JunB (Origene Technologies, Inc.) was determined using BIAcore 3000 (BIAcore, Inc.) and the data were analyzed using BIAEVALUTION software version 4.1 (BIAcore, Inc.). Standard ethyl(dimethylaminopropyl) carbodiimide/N-hydroxysuccinimide coupling was used to covalently immobilize JunB to CM5 sensor chips (BIAcore, Inc.) according to the manufacturer's instructions, and the interaction was detected in HBS-EP buffer (10 mM HEPES, pH 7.4, 0.15 M NaCl, 3 mM EDTA, $0.005 \%$ v/v surfactant
P20). Flow cell 1 was left blank as a NC. Association rates were measured under a continuous flow of $10 \mu \mathrm{l} / \mathrm{min}$ using His-ATF3 at concentrations ranging between 30-150 nM plus a concentration of $0 \mathrm{nM}$, and the data were fitted using 1:1 Langmuir binding with no bulk refractive shift.

In vitro His-tag pulldown assay. Cell lysates containing His-ATF3 were prepared from the bacteria harboring pET32a-ATF3 plasmid after induction by IPTG for $4 \mathrm{~h}$ via sonication $\left(0^{\circ} \mathrm{C}, 20 \mathrm{KHz}\right.$, output $3 ; 50 \%$ duty cycle; $\left.15 \mathrm{~min}\right)$ and incubated with $100 \mu \mathrm{l}$ Ni-NTA agarose resin (Sigma-Aldrich; Merck $\mathrm{KGaA}$ ) at $4^{\circ} \mathrm{C}$ overnight. After washing twice with PBS, bound proteins were boiled in the loading buffer, separated using $12 \%$ SDS-PAGE and detected by WB as aforementioned.

Co-immunoprecipitation (Co-IP) assay. Plasmids pCMV-Script-HA-ATF3 and pCMV-Script-Myc-JunB were prepared for the assay via inserting hemagglutinin (HA) or Myc sequence before the ORFs of ATF3 and JunB, respectively. For the Co-IP assay, HEC-1B-NC, HEC-1B-ATF3 
or $293 \mathrm{~T}$ cells (Chinese Academy of Sciences Committee Type Culture Collection) were transfected with $2.5 \mu \mathrm{g}$ pCMV-Script-HA-ATF3 or pCMV-Script-Myc-JunB vector as aforementioned, respectively. After $24 \mathrm{~h}$, cells were collected and then lysed in IP assay lysis buffer [10 mM Tris- $\mathrm{HCl}(\mathrm{pH} 7.3)$, $100 \mathrm{mM} \mathrm{NaCl}, 1 \mathrm{mM}$ EDTA, 0.2\% Triton X-100, $0.2 \mathrm{mM}$ dithiothreitol (DTT), 10\% glycerol and protease inhibitors]. Cell lysates $(1 \mathrm{mg})$ were incubated with $1 \mu \mathrm{g}$ JunB antibody (1:50; cat. no. sc-8051; Santa Cruz Biotechnology, Inc.) or $1 \mu \mathrm{g}$ immunoglobulin G1 (1:50; IgG1; cat. no. 401401; Biolegend, Inc.) as a control at $4^{\circ} \mathrm{C}$ overnight. The immunocomplex was precipitated with $25 \mu \mathrm{l}$ Protein A Sephasrose 6MB (Cytiva), pelleted at $800 \times \mathrm{g}, 4^{\circ} \mathrm{C}$ for $5 \mathrm{~min}$, washed with $1 \mathrm{ml} \mathrm{IP}$ assay buffer supplemented with $300 \mathrm{mM} \mathrm{NaCl}$ three times and then detected using 12\% SDS-PAGE and WB as aforementioned with anti-ATF3 antibody and anti-JunB antibody.

Co-localization assay. HEC-1B cells were seeded at a confluency of $80 \%$ on a glass slip and co-transfected with $5 \mu \mathrm{g}$ pCMV-Script-HA-ATF3 and pCMV-Script-Myc-JunB plasmid, respectively, with Lipofectamine ${ }^{\circledR} 3000$ (Invitrogen; Thermo Fisher Scientific, Inc.). The plasmids were prepared as aforementioned. After $24 \mathrm{~h}$, cells were fixed in $4 \%$ formaldehyde for $15 \mathrm{~min}$ at $4^{\circ} \mathrm{C}$, permeabilized with $0.2 \%$ Triton $\mathrm{X}-100$ for $5 \mathrm{~min}$ at room temperature and blocked with $5 \%$ bovine serum albumin (cat. no. A7906; Sigma-Aldrich; Merck KGaA) for $50 \mathrm{~min}$ at room temperature. Cells were subsequently incubated with ATF3 (C-19) antibody (1:200; cat. no. sc-188; Sant Cruz Biotechnology. Inc.) and JunB antibody (1:200; cat. no. sc-8051; Santa Cruz Biotechnology, Inc.) at $4^{\circ} \mathrm{C}$ overnight and then labeled with FITC-conjugated anti-rabbit IgG (1:20,000; cat. no. 111-095-003; Jackson ImmunoResearch Laboratories, Inc.) and rhodamine (TRITC)-conjugated anti-mouse IgG (1:20,000; cat. no. 115-025-146; Jackson ImmunoResearch Laboratories, Inc.) for $1 \mathrm{~h}$ at room temperature. After washing with PBS three times, $30 \mathrm{sec}$ each time, cells were counterstained with DAPI at room temperature for $10 \mathrm{~min}$. After washing with PBS, cells were covered with Vectashield mounting media (Vector Laboratories, Inc.). Images were acquired with a laser scanning confocal microscope (Leica Microsystems, Inc.) using a x60 oil immersion lens.

Cell proliferation and colony formation assays. To assess cell proliferation, cells were seeded into 96-well plates at 2,000 cells per well. At the time points of 1,2,3,4 and 5 days, the number of metabolically active cells was measured using a MTT assay (Sigma-Aldrich; Merck KGaA). With the formed formazan dissolved in $100 \mu \mathrm{l}$ dimethyl sulfoxide, the absorbance values were measured at $490 \mathrm{~nm}$ with a Spectra Max 190 microplate reader (model 680; Bio-Rad Laboratories, Inc.).

For colony formation assays, cells were seeded in 6-well plates at 200 cells/well and grown in normal culture medium (DMEM/F12 with $10 \% \mathrm{FBS}$ ) at $37^{\circ} \mathrm{C}$ and $5 \% \mathrm{CO}_{2}$ for 9 days for colony formation. Colonies were fixed in $4 \%$ formaldehyde for $30 \mathrm{~min}$ at room temperature and then counted under a light microscope (magnification, x40; Eclipse Ts2; Nikon Corporation) after staining with $0.5 \%$ crystal violet for $20 \mathrm{~min}$ at room temperature. The experiments were repeated independently $\geq 3$ times.
Chromatin IP (ChIP) assay. Cells with or without overexpression of ATF3 were fixed at room temperature in $0.5 \%$ formaldehyde for $20 \mathrm{~min}$. After sonication $\left(0^{\circ} \mathrm{C} ; 20 \mathrm{KHz}\right.$; output 2; $20 \%$ duty cycle; $5 \mathrm{~min}$ ) using a sonifier (Model 450; Branson; Thermo Fisher Scientific, Inc.), IP was performed at $4^{\circ} \mathrm{C}$ overnight using $5 \mu \mathrm{g}$ anti-ATF3 (1:50; cat. no. sc-87213; Santa Cruz Biotechnology, Inc.), anti-JunB antibody (1:50, cat. no. sc-8051; Santa Cruz Biotechnology, Inc.) or control mouse IgG1 (1:50; cat. no. 401401; Biolegend, Inc.). Pulled-down chromatins were denatured at $65^{\circ} \mathrm{C}$ overnight and the DNA was purified using the QIAquick purification column (size, $0.6 \mathrm{ml}$; Cytiva). The resulting AP-1 site included DNA was quantified by qPCR as aforementioned using the following primer pairs: Forward, 5'-TAACTGCTCGGAAGT CCCAC-3' and reverse, 5'-ACCCGACTATCTGCCAGG TC-3'. Fluorescence intensities were calculated using the following formula: Fluorescence intensity $=$ (IP average \pm IgG average)/(Input average).

Transwell migration and invasion assays. For Transwell migration assays, the lower surface of polycarbonate membranes of the inserts $(8-\mu \mathrm{m}$ pore size; Corning, Inc.) was coated with $100 \mu \mathrm{g}$ fibronectin (Sigma-Aldrich; Merck KGaA). A total of $2 \times 10^{5}$ cells suspended in $100 \mu \mathrm{l}$ DMEM/F12 medium (without FBS) were dispensed into the upper chambers of the Transwells (with $0.6 \mathrm{ml}$ DMEM/F12 medium supplemented with $10 \% \mathrm{FBS}$ in the lower chamber) and incubated at $37^{\circ} \mathrm{C}$ for $24 \mathrm{~h}$. Cells migrated to the lower membrane surface were fixed at room temperature for $20 \mathrm{~min}$ with $4 \%$ paraformaldehyde, stained with crystal violet (20 min at room temperature) and counted under a light microscope (magnification, x40; Eclipse Ts2; Nikon Corporation). For invasion assays, $10^{6}$ cells were plated in Transwells coated with Matrigel (1:6; BD Biosciences) at room temperature for $1 \mathrm{~h}$ and cultured at $37^{\circ} \mathrm{C}$ for $24 \mathrm{~h}$. Invaded cells were stained and counted as aforementioned.

Apoptosis assay and cell cycle analysis. The apoptotic-related proteins were detected using WB as aforementioned. To measure the apoptosis ratios using flow cytometry, a total of $1 \times 10^{6}$ HEC-1B-NC or -ATF3 cells were digested with $0.25 \%$ trypsin (without EDTA) and stained with FITC-Annexin V in fluorescence-assisted cell sorting buffer (cat. no. 556547; BD Biosciences) for $30 \mathrm{~min}$ at room temperature after washing with PBS. The total apoptotic (early and late apoptosis) cells were then analyzed with the software Kaluza 1.3 (Beckman Coulter, Inc.) on a Beckman Gallios flow cytometer (Beckman Coulter).

For the cell cycle analysis, cells were fixed with $4 \%$ paraformaldehyde at room temperature for $2 \mathrm{~h}$ and stained with 7-aminoactinomycin D at room temperature for $10 \mathrm{~min}$. After the cells were detected by flow cytometry (Beckman Gallios; Beckman Coulter, Inc.), cell cycle analysis was performed with the software Kaluza version 1.3 (Beckman Coulter, Inc.). Experiments were performed in as three independent replicates.

Caspase enzymatic activity measurement. The activities of Caspase-3/7, Caspase- 8 and Caspase- 9 were determined using the Caspase-Glo 3/7 Assay kit, Caspase-Glo 8 Assay kit and the Caspase-Glo 9 Assay kit (Promega Corporation), 
respectively, according to the manufacturer's protocol. HEC-1B-NC, HEC-1B-ATF3, AN3CA-NC and AN3CA-ATF3 cells were seeded at a density of $4 \times 10^{5}$ cells/well in 6 -well plates and cultured overnight. Following digestion, $\sim 6 \times 10^{4}$ cells per sample were collected in 1.5-ml tubes. After $100 \mu \mathrm{l}$ Caspase-Glo reagent (relative caspase substrate) was added to each sample, the cells were thoroughly mixed and incubated for $1 \mathrm{~h}$ in the dark at $37^{\circ} \mathrm{C}$. Luminescence values of each sample were measured using an IVIS Kinetic Imaging System (Caliper Life Sciences; PerkinElmer, Inc.). The quantitative analysis was performed based on the relative caspase activities and normalized to the raw luminescence units of the untreated control.

$J u n B$ reporter assay. JunB promoter constructs driving the expression of the luciferase reportergene were used.ADNA fragment of the WT or mutant (MT) 5'untranslated region (UTR) of JunB was cloned into the pRL-CMV luciferase reporter plasmid (50 ng; cat. no. E2261; Promega Corporation) and the resultant vectors were designated as 'pRL-CMV-JunB-5'UTR-WT' and 'pRL-CMV-JunB-5'UTR-MT', respectively. HEC-1B-NC or HEC-1B-ATF3 cells were transiently transfected with $1 \mu \mathrm{g}$ Renilla constructs (as an internal control) or plasmids pRL-CMV-JunB-5'UTR-WT or pRL-CMV-JunB-5'UTR-MT using Lipofectamine ${ }^{\circledR} 3000$ as aforementioned. Cell lysates were prepared after $24 \mathrm{~h}$ and the luciferase activities of cell lysates were then determined using a luminometer (Glomax 96; Promega Corporation). The relative luciferase activity was calculated as firefly/Renilla. All experiments were performed as $\geq 3$ independent replicates.

DNA precipitation (DNAP) assay. Nuclear extracts $(100 \mu \mathrm{g})$ in $500 \mu \mathrm{l}$ nuclear extraction buffer (Thermo Fisher Scientific, Inc.) from HEC-1B-NC or HEC-1B-ATF3 cells were mixed with a biotinylated activator protein (AP)-1 site probe (50 pmol; cat. no. D3118; Beyotime Institute of Biotehcnology) in a buffer [HEPES-KOH ( $\mathrm{pH} 7.9), 80 \mathrm{mM} \mathrm{KCl}, 1 \mathrm{mM}$ $\mathrm{MgCl}$, $0.2 \mathrm{mM}$ EDTA, $0.5 \mathrm{mM}$ DTT, 10\% (w/v) glycerol, $0.1 \%$ Triton $\mathrm{X}-100$ and $1 \mu \mathrm{g}$ poly $(\mathrm{dI}-\mathrm{dC})]$ at $0^{\circ} \mathrm{C}$ for $30 \mathrm{~min}$. Then, $100 \mu \mathrm{l}$ Streptavidin agarose beads (Sigma-Aldrich; Merck KGaA) were added and the mixture $(0.6 \mathrm{ml})$ was gently agitated for $1 \mathrm{~h}$ at room temperature. Beads were then pelleted at $800 \mathrm{x} \mathrm{g}$ for $5 \mathrm{~min}$ at room temperature and washed three times with PBS, and the bound proteins were analyzed using WB as aforementioned. The sequence of the biotinylated AP-1 site used was as follows: 5'-TATGGAGATGACTCAAAG GGGGCGTGCA-3'.

Xenograft assay in nude mice. A total of $12 \mathrm{BALB} / \mathrm{c}$ nude mice (age, 4-5 weeks; weight 16-18 g) were purchased from Shanghai Laboratory Animal Research Center. The mice were housed in individually ventilated cages on a ventilated rack (Model GH; Suzhou Fengshi Laboratory Animal Equipment Co., Ltd.) in a specific pathogen-free facility with $12 \mathrm{~h}$ cycle of light/dark. The temperature, humidity and air flow of the ventilating air was set at $22^{\circ} \mathrm{C}, 40 \%$ and $25 \mathrm{~cm} / \mathrm{sec}$, respectively. The animals were able to move freely with unlimited access to water and food. A total of $5 \times 10^{6}$ cells suspended in $100 \mu 11 \mathrm{X}$ PBS were injected into the interscapular area subcutaneously of the mice. A group of mice $(n=8)$ received HEC-1B-ATF3 (referred to as exATF3). Another NC group $(n=4)$ received
HEC-1B-NC cells transfected with control plasmid (cloning vector only, referred to as exNC). The sizes of tumors were measured daily over 4 weeks. Mice were sacrificed at 30 days post-injection by $\mathrm{CO}_{2}$ exposure at an air displacement rate of $30 \%$ per min. Tumors were excised and measured. The tumor volume $\left(\mathrm{cm}^{3}\right)$ was calculated by using the following formula: Volume $=($ longest diameter $) \times(\text { shortest diameter })^{2} \times 0.5$.

Statistical analysis. All statistical analyses were performed using SPSS 16.0 (SPSS, Inc.) or GraphPad Prism 5.0 (GraphPad Software, Inc.). Each experiment was performed $\geq 3$ times and data are presented as the mean \pm SD. A one-tailed, unpaired Student's t-test or Mann-Whitney U-test were utilized to determine significant differences between the treatment groups. $\mathrm{P}<0.05$ was considered to indicate a statistically significant difference.

\section{Results}

ATF3 is downregulated and JunB is upregulated in EC. The expression levels of ATF3 and JunB were semi-quantitatively assessed using WB, indicating that ATF3 expression was low in EC tissues; it was $>20$-fold lower compared with healthy endometrium. However, JunB expression was relatively high, with a $\sim 2$-fold increase compared with healthy tissues (Fig. 1A). To further evaluate this result, healthy endometrial and EC tissues were subjected to immunohistochemical analysis. Strong staining for JunB and weak staining for ATF3 were observed in EC tissues (Fig. 1B). Thus, the results indicated that ATF3 was downregulated, while JunB was upregulated in EC.

Next, ATF3 and JunB expression levels were assessed in EC cell lines. WB analysis demonstrated that JunB was expressed in the type I and type II EC cell lines HEC-1B and AN3CA, while the expression of ATF3 was low, which was consistent with the WB and immunohistochemistry results (Fig. 1C).

ATF3 overexpression impacts the proliferation, cell cycle, apoptosis, migration and invasion of tumor cells in vitro. Following the identification of the low expression of ATF3 in ECs, HEC-1B cells were transfected to stably overexpress ATF3 in order to demonstrate the function of ATF3 in endometrial tumorigenesis. Stable transfection significantly increased the mRNA transcription of ATF3 by $>180$-fold (Fig. S1) and its protein expression by $\sim 9$-fold in HEC-1B cells (Fig. 2A). After transfection, the proliferation and colony-forming ability of HEC-1B cells was assessed using a MTT assay and a colony formation assay, respectively. The results suggested that overexpression of ATF3 in HEC-1B cells significantly inhibited cell proliferation (Fig. 2B) and colony formation (Fig. 2C) compared with exNC cells.

ATF3 is closely associated with the cell cycle, apoptosis, invasion and metastasis in certain tumor types (16-18). Therefore, it was investigated whether overexpression of ATF3 was able to change the cell cycle profile and trigger apoptosis in exATF3 cells. The flow cytometry results demonstrated that exATF3 cells had a markedly increased G1 phase population $(60.9 \pm 3.0 \%$; $n=3)$, while the $S(12.2 \pm 0.7 \%$; $n=3)$ and $\mathrm{G} 2$ phase $(25.9 \pm 3.7 \%, n=3)$ populations were decreased, compared with those in exNC cells $(41.2 \pm 3.2,20.3 \pm 3.8$ and $38.5 \pm 2.1 \%$, respectively; n=3; Fig. 2D). 
A

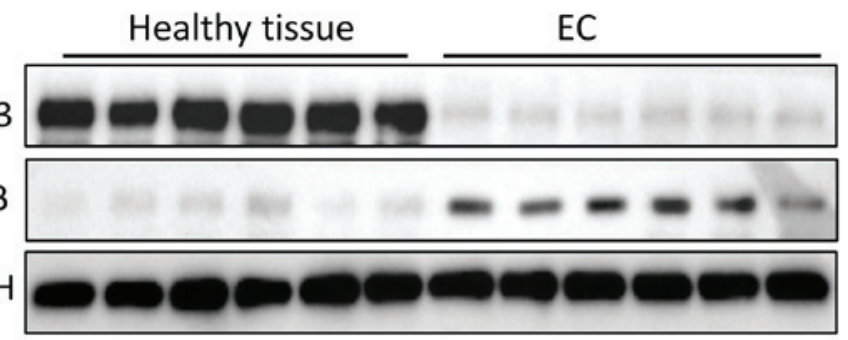

B
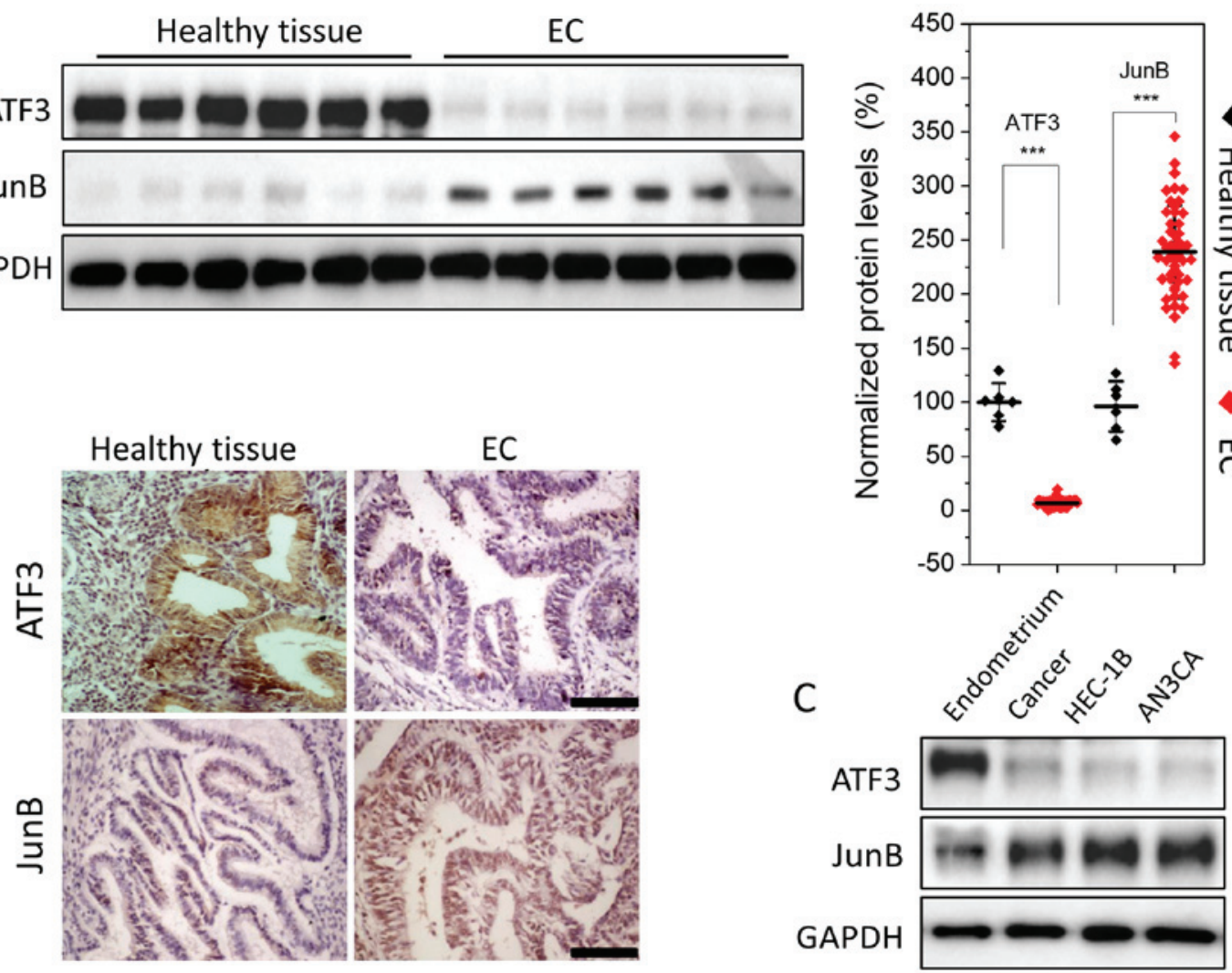

Figure 1. Lower ATF3 and higher JunB expression levels in ECs and EC cell lines compared with healthy endometrium tissues and the primary cells. (A) Detection of ATF3 and JunB in healthy endometrium tissues $(n=6)$ and EC $(n=50)$ using WB. The semi-quantitative analysis was performed based on the gray intensity against GAPDH, normalized to healthy endometrium tissues. (B) Immunohistochemical analysis of ATF3 and JunB expression levels in healthy endometrium and EC (magnification, x200). There was high staining of ATF3 in healthy endometrium and low staining in EC, while weak expression of JunB in healthy endometrium and strong expression in EC. (C) Expression levels of ATF3 and JunB protein in EC primary cells and two EC cell lines were measured using WB. JunB was highly expressed in HEC-1B and AN3CA cell lines, while ATF3 was lowly expressed in these two cell lines compared with normal endometrial primary cells. Data are presented as the mean $\pm \mathrm{SD}$ ( $\mathrm{n}=3$ unless otherwise specified), and were analyzed using one-tailed Student's t-test. All experiments were repeated in triplicate. ${ }^{* * *} \mathrm{P}<0.001$. ATF3, activating transcriptional factor 3; EC, endometrial carcinoma; WB, western blotting.

The cells of exNC and exATF3 were further analyzed with FITC-Annexin V staining and were subjected to analysis of early and late apoptotic cell percentages using flow cytometry. The results indicated that a greater percentage of exATF3 cells $(4.6 \pm 1.1 \%)$ were apoptotic compared with exNC cells $(1.0 \pm 0.6 \%$; Fig. 2E). In addition, cells transfected with ATF3 demonstrated a significantly reduced migratory and invasive abilities compared with the control cells (Fig. 2F). Collectively, the results suggested that ATF3 had a suppressive function in ECs.

Overexpression of ATF 3 regulates the expression of apoptotic markers, MMPs and TIMPs. After the inhibitory effects of ATF3 on the proliferation, transmigration and invasion of ECs were identified, it was further investigated whether apoptotic signaling pathways were activated; thus, changes in the levels of apoptotic markers after overexpression of ATF3 in ECs were detected. The enzymatic activity of Caspases is regarded as an important indicator of apoptosis (19). Therefore, the activities of Caspase-3/7, Caspase- 8 and Caspase- 9 were first measured, and it was found that the activities of all of these enzymes increased after ATF3 was overexpressed in the cells (Fig. 3A). In addition, the expression levels apoptotic-associated proteins, including cleaved PARP, Bax and p-p38 increased, while $\mathrm{Bcl} 2$, and $\mathrm{Bcl}-\mathrm{x}$ decreased in the two cell lines (Fig. 3B). Thus, these results may explain the increased apoptotic ratios of host cells after overexpression of ATF3. Moreover, the relative protein levels of p-p38 and p38 were found to be significantly increased, indicating that apoptosis may be mediated via a p38-mitogen-activated protein kinase signaling pathway (Fig. 3B).

MMPs and TIMPs have prominent roles in cancer invasion and metastasis. TIMPs, binding to MMPs at a 1:1 molar ratio, are able to block the access of substrates to the catalytic domain of endopeptidases and eventually inhibit the bioactivities of MMPs (20). Furthermore, increases in the MMP/TIMP ratio have been reported to affect invasion and metastasis, and are widely considered as a marker for cancer invasion (21-23). Therefore, the mRNA expression levels of MMPs and TIMPs in both cell lines with and without ATF3 overexpression were compared. It was identified that certain MMPs, including MMP9, MMP10 and MMP13, were significantly downregulated following overexpression of ATF3 (Fig. 3C and D); MMP7 was slightly upregulated, but was not significantly different compared with the control. However, the expression levels of all TIMPs were not significantly different after ATF3 was overexpressed and remained stable.

Overexpression of ATF3 decreases the tumor size in a xenograft model. To further study the anti-tumor potential of ATF3, 
A

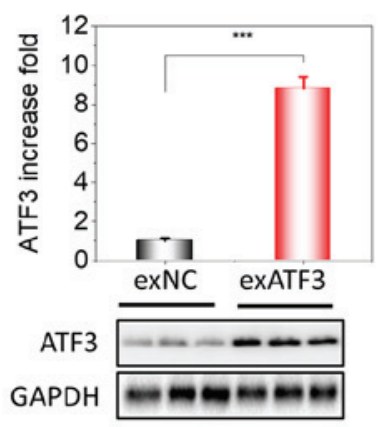

B

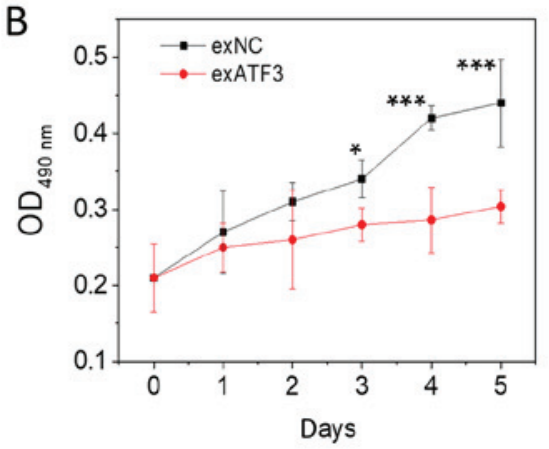

D
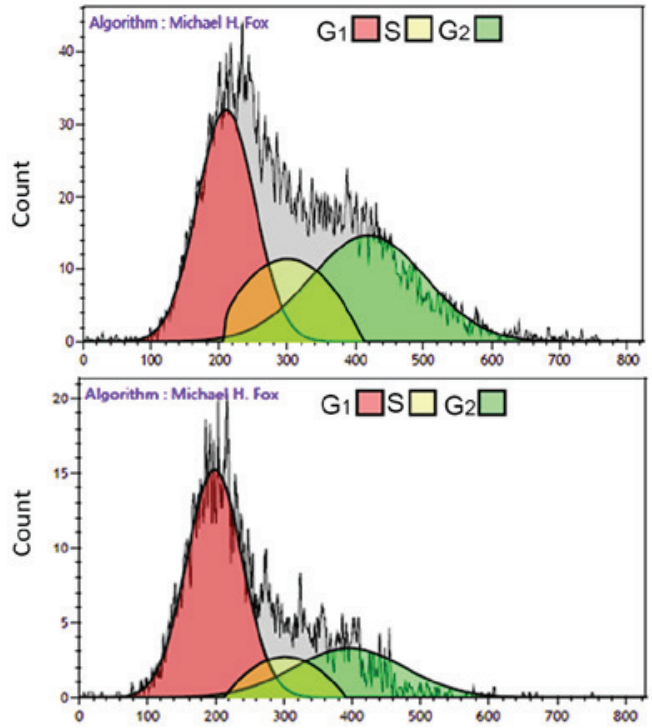

$\mathrm{F}$

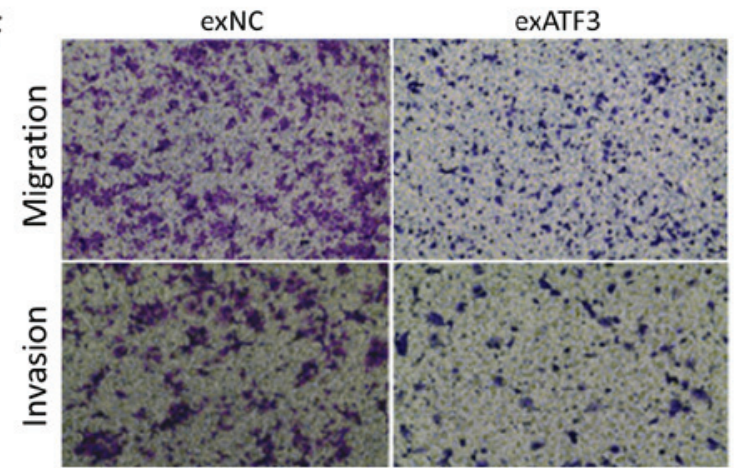

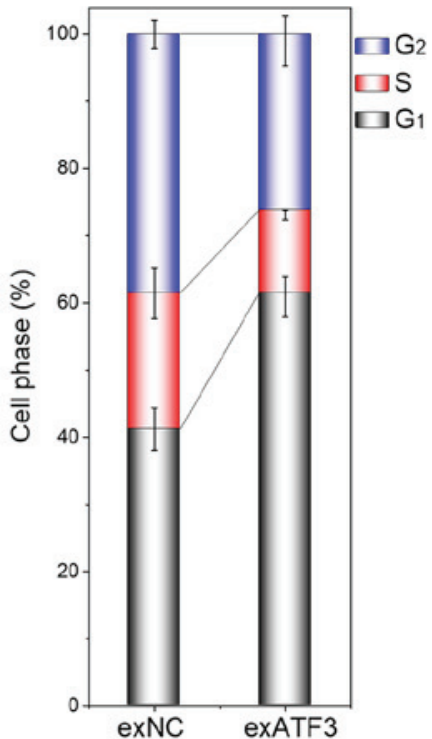

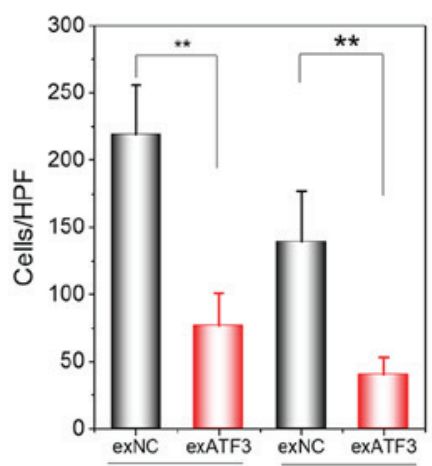

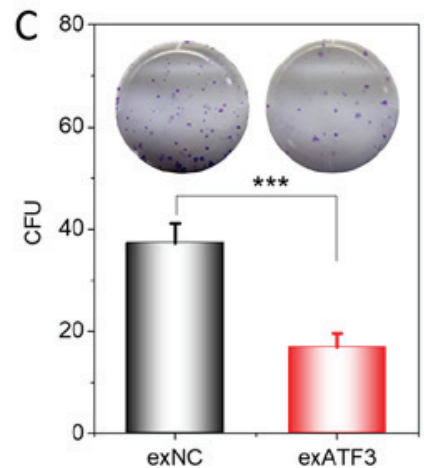

$E$
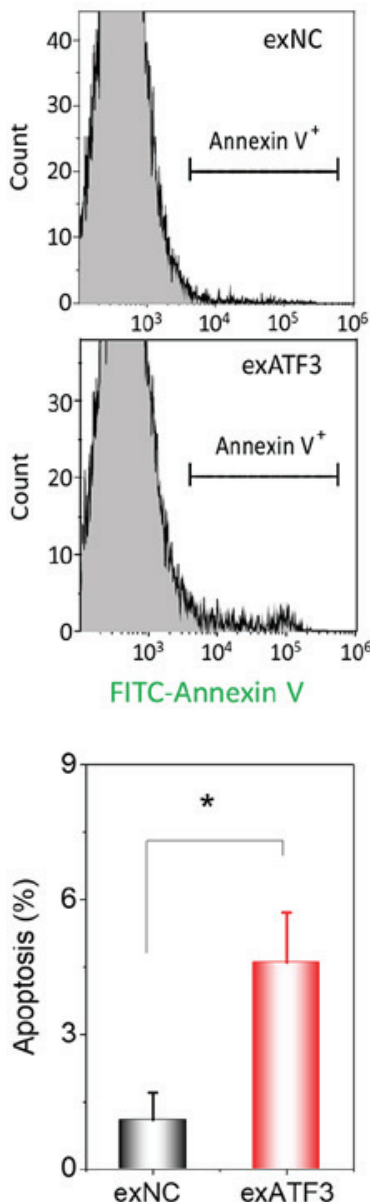

Figure 2. ATF3 overexpression inhibits proliferation, migration and invasion of HEC-1B cells. (A) Assessment of ATF3 protein expression in exATF3 cells after stable transfection. (B) Assessment of the cell proliferation of exNC and exATF3 cells. (C) Colony-formation assays of exATF3 and exNC cells, and graphical representation of the numbers of colonies in three independent experiments. (D) Cell cycle determined using flow cytometry and the quantitative analysis. (E) Representative images of flow cytometry analysis of apoptotic rates of exNC and exATF3 cells. The apoptotic cells were stained with FITC-Annexin V. (F) Cell migration and invasion assay of exNC and exATF3 cells, and graphical representation of the numbers of migrated and invaded cells in three independent experiments (magnification, $\mathrm{x} 40$ ). Data are presented as the mean $\pm \mathrm{SD}(\mathrm{n}=3)$ and were analyzed using one-tailed Student's t-test. "P<0.05, ${ }^{* *} \mathrm{P}<0.01,{ }^{* * * *} \mathrm{P}<0.001$ vs. controls. ATF3, activating transcriptional factor 3; exATF3, exogeneous ATF3 high expression cells; OD, optical density; NC, negative control; exNC, negative control cells of exATF3; HPF, high-power field; CFU, colony forming unit.

a xenograft tumor growth assay in nude mice subcutaneously injected with stably transfected exATF3 or exNC cells was performed. The results indicated that overexpression of ATF3 significantly decreased the volume and weight of the xenograft tumors compared with the exNC group (Fig. 4A).

To determine the effect of ATF3 on proliferation and apoptosis, immunohistochemical of staining of the tumor tissues for Ki67 and PCNA was performed. The expression of $\mathrm{Ki67}$, indicative of tumor cell proliferation, was decreased by
exATF3 in the xenograft tumors. Moreover, notably weaker PCNA staining was detected in the exATF3 group compared with the exNC group (Fig. 4B).

Overexpressed ATF3 directly interacts with JunB and binds to AP-1 sites in ECs. The expression of ATF3 and JunB (Fig. S2) in EC was visualized by confocal microscopy. ATF3 and JunB were identified to be predominantly localized in the nucleus of EC cells (Fig. 5A). Previously, the binding 
A
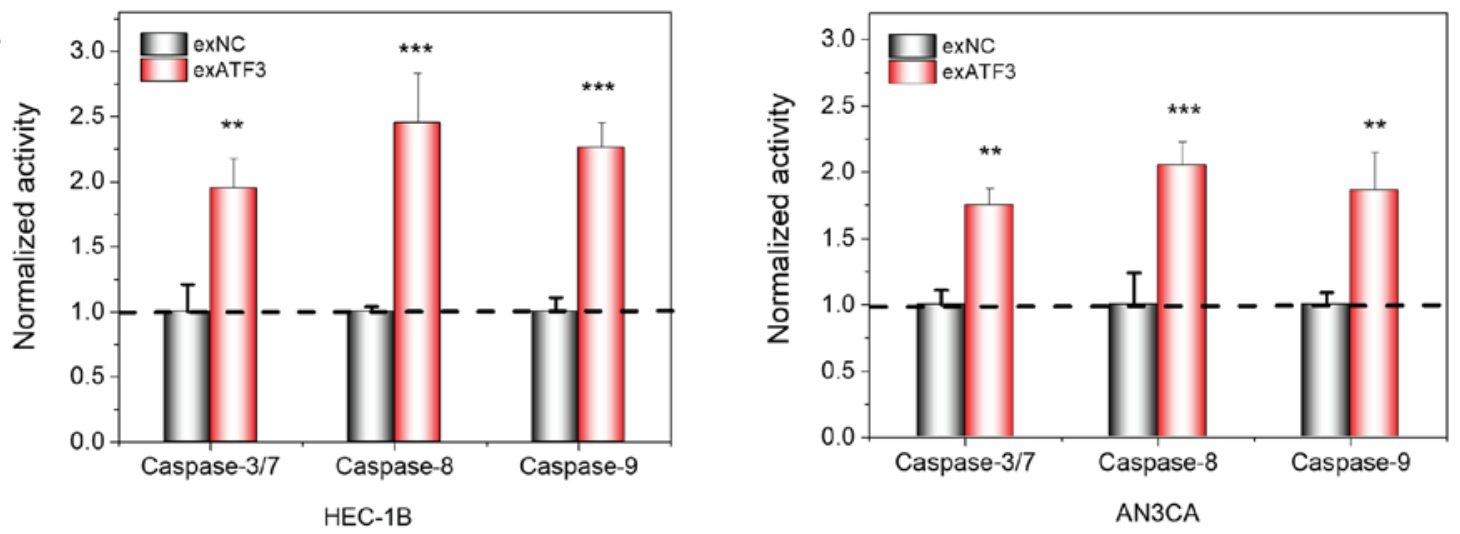

B
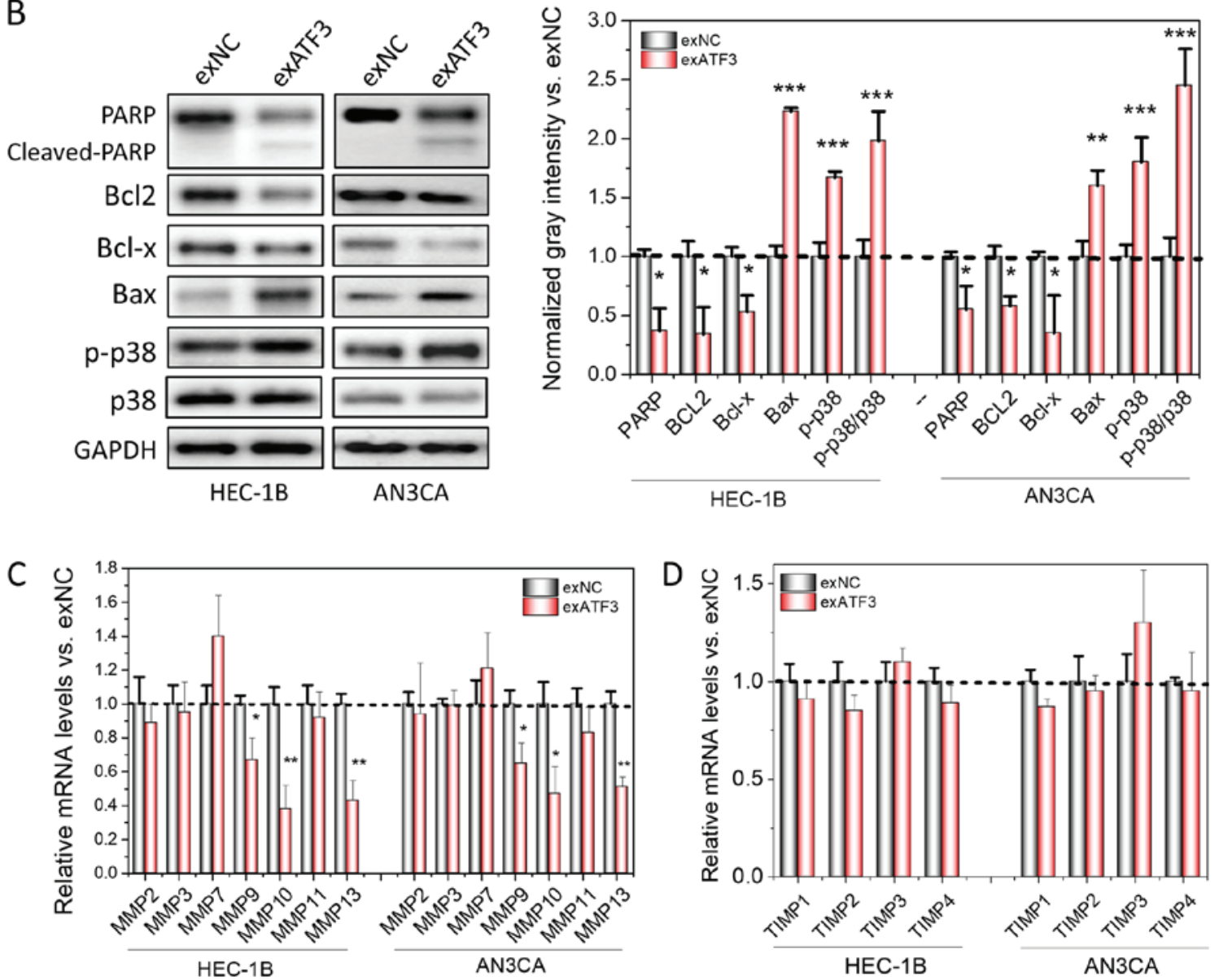

Figure 3. Overexpression of ATF3 induces apoptosis and loss of MMPs in cancer cell lines. (A) Measurement of apoptotic-related Caspase 3/7, 8 and 9 activities using spectrometry in ATF3-overexpressed HEC-1B and AN3CA cells, normalized to the activities of control. (B) Apoptosis marker detection using western blotting. The semi-quantitation analysis was performed based the gray intensities, normalized to GAPDH. mRNA levels of MMPs (C) and TIMPs (D) were determined by reverse transcription-quantitative PCR. The quantitation analysis was normalized to control. Data are presented as the mean \pm SD $(\mathrm{n}=3)$ and were analyzed using one-tailed Student's t-test. ${ }^{*} \mathrm{P}<0.05,{ }^{* *} \mathrm{P}<0.01,{ }^{* * *} \mathrm{P}<0.001$ vs. exNC. ATF3, activating transcriptional factor 3; MMP, matrix metallopeptidase; TIMP, tissue inhibitors of metalloproteinase; PARP, poly(ADP-ribose) polymerase; p-, phosphorylated.

partners of ATF3 had been screened in a protein library of ECs using $\mathrm{Y} 2 \mathrm{H}$ analysis and JunB was identified as one of its interactors (Fig. S3A and B). In addition, their interaction was demonstrated in vitro using Co-IP (Fig. S3C). To prepare the recombinant protein of ATF3, a prokaryotic expression plasmid, pET32a-ATF3, was constructed and His-ATF3 was expressed in bacteria. The bioactive His-ATF3 was obtained after affinity purification and denaturation. Using the His-ATF3, the interaction was assessing with a His-tag pulldown assay (Fig. S3D).
The presence of an ATF3/JunB interaction in ECs after ATF3 overexpression was assessed using Co-IP with monoclonal anti-ATF3 antibodies. In the native HEC-1B cells, no interaction between ATF3 and JunB was detected. However, from HEC-1B cells stably overexpressing ATF3, JunB was precipitated, indicating that the ATF3-JunB interaction only occurs in the ATF3-overexpressing cells (Fig. 5B).

To measure the affinity capacity between ATF3 and JunB, which represents the minimum concentrations of His-ATF3 or JunB required for binding, the association rate constant $(\mathrm{Ka})$ 

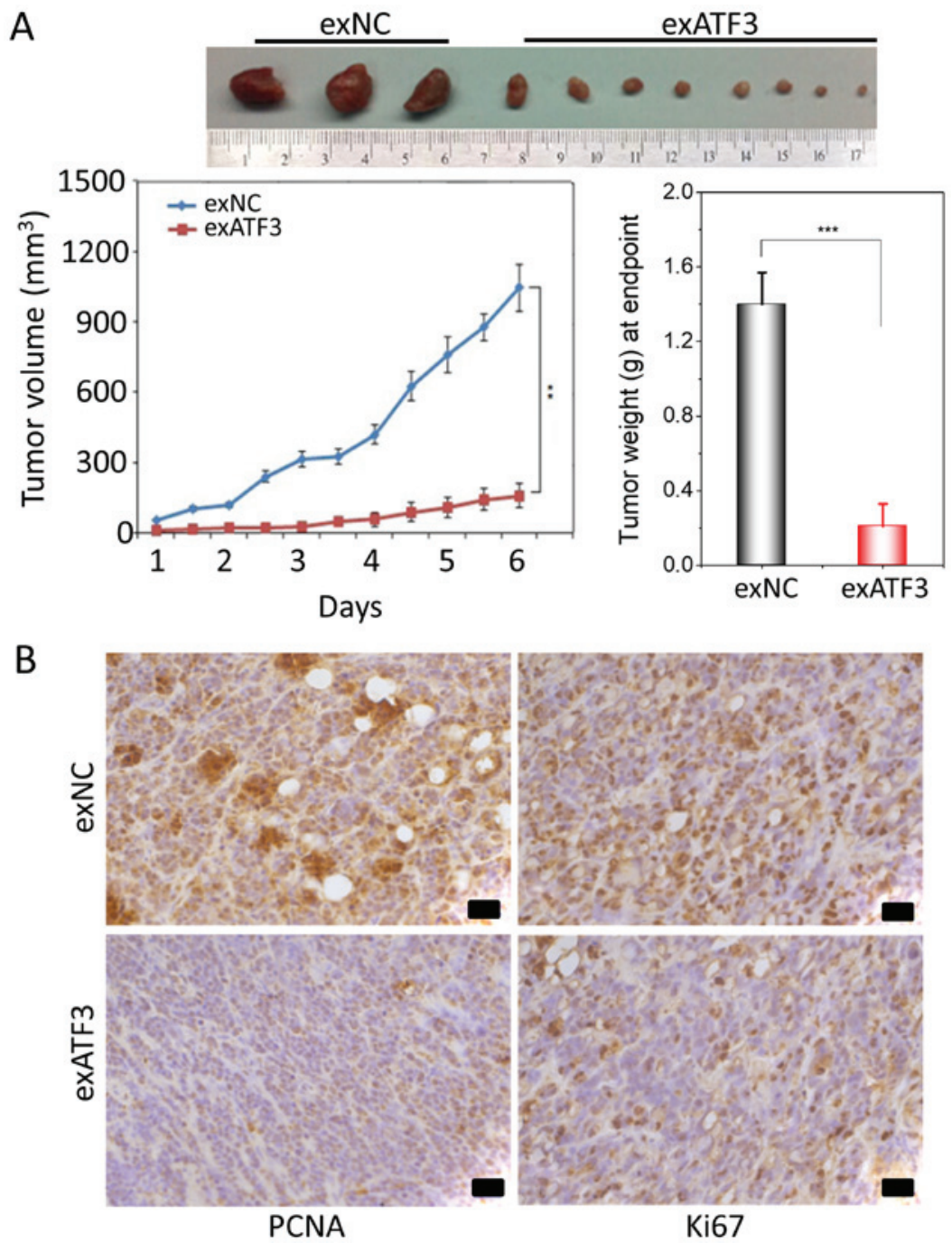

Figure 4. Overexpressing ATF3 decreases tumor growth in a mouse xenograft model. (A) Stable transfection of exATF3 and exNC cells. Tumors of mice injected with ATF3-transfected HEC-1B cells were removed 6 weeks after injection. Weights of tumors at the endpoint. Volumes of each tumor measured each week for 6 weeks. (B) Immunohistochemical staining of Ki67 and PCNA in the exATF3 and exNC xenograft tumors. Scale bar, $50 \mu$ m. Data are presented as the mean $\pm \mathrm{SD}(\mathrm{n}=3)$ and were analyzed using one-tailed Student's t-test. ${ }^{* *} \mathrm{P}<0.01,{ }^{* * * *} \mathrm{P}<0.001$. ATF3, activating transcriptional factor 3 ; PCNA, Proliferating cell nuclear antigen; NC, negative control.

and $\mathrm{Kd}$ of the interaction between His-ATF3 and JunB were determined with a BIAcore instrument. Fitting the data to a 1:1 binding model yielded an apparent binding affinity with the equilibrium dissociation constant $\mathrm{KD}=1.9 \times 10^{-8} \mathrm{M}$, obtained from the ratio of the rate constants $\mathrm{k}_{\mathrm{d}} / \mathrm{k}_{\mathrm{a}}$ (Fig. $5 \mathrm{C}$ ).

Similar to the composition of the promoters of most MMPs (24,25), an AP-1 site is located in the promoter of JunB. WB analysis indicated that JunB was downregulated $\sim 3$-fold by overexpression of ATF3 (Figs. 5D and S4). To demonstrate that the downregulation of JunB was exerted by ATF3, luciferase plasmids with JunB promoter containing a WT AP-1 site or a MT AP-1 site at $-2,322$ to $-2,315$ were constructed (Fig. 5E). The highest luciferase activity was observed in the HEB-1C cells transfected with the plasmid containing the WT AP-1 binding site, and only slight or background bioactivities were measured when no AP-1 sites or a MT AP-1 site were included. In addition, the luciferase activity exhibited a significant decrease when ATF3 overexpression plasmid was co-transfected with reporter plasmid containing the WT AP-1 binding site. Furthermore, no difference in luciferase activity was identified between the groups transfected with exATF3 or exNC co-transfected with plasmid containing MT AP-1 biding sites or without promoter. Thus, the results indicated that the overexpression of ATF3 regulated JunB transcription and translation via binding to the AP-1 site in the promoter of JunB.

To demonstrate that the binding of ATF3 requires the presence of JunB, ChIP was performed. The JunB promoter DNA sequence was precipitated when either anti-ATF3 or anti-JunB antibodies were utilized for precipitation (Fig. 5F). In addition, the levels of precipitated DNA were in parallel with the expression levels of ATF3 or JunB. When DNA was precipitated with the AP-1 binding site, ATF3 and JunB were precipitated together alone with the DNA, indicating that ATF3 regulated AP-1 signaling by interacting with JunB (Fig. 5G).

\section{Discussion}

$\mathrm{EC}$ is one of the most common cancer types of the female genital tract worldwide (1). While it is known that in the 
A

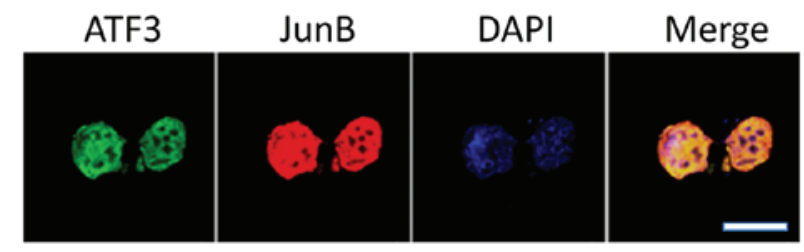

B

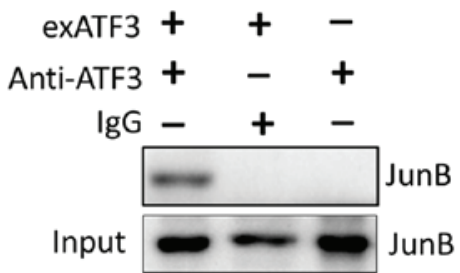

D

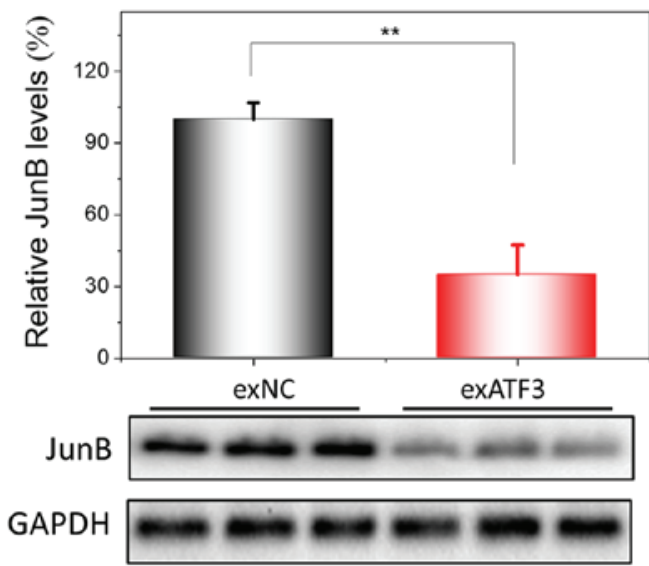

GAPDH
C

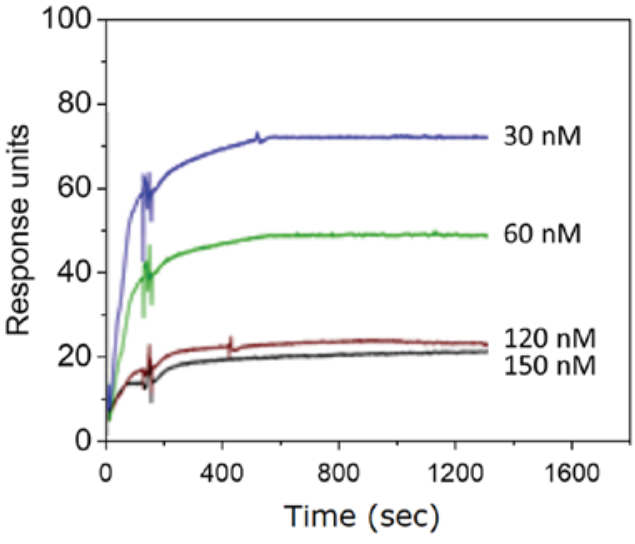

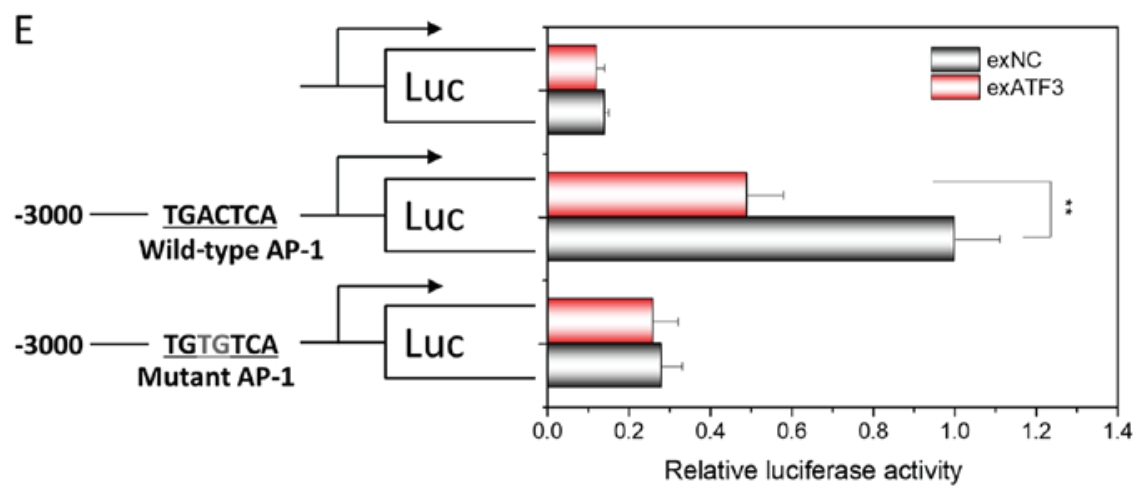

G

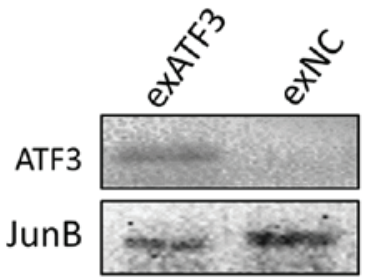

Figure 5. ATF3 interacts to JunB in endometrial carcinoma cells and their binding to AP-1 site. (A) Subcellular colocalization of ATF3 and JunB in exATF3 cells. Nuclei were stained using DAPI. Scale bar, $7.5 \mu \mathrm{m}$. (B) Interaction between ATF3 and JunB in exATF3 was assessed using co-immunoprecipitation. (C) BIAcore assay of the interaction between His-ATF3 and JunB. The values for association rate constant and disassociation rate constant (Kd) were calculated from sensorgrams using four concentrations of His-ATF3. The binding affinity of $\mathrm{Kd}=1.9 \times 10^{-8} \mathrm{M}$. (D) JunB was downregulated by ATF3 overexpression in HEC-1B cells. The semi-quantitation was performed based on band gray intensities, normalized to the intensities before overexpression. (E) The cells of exATF3 orexNC cells were transfected with reporter plasmids, pCMV-RL for $24 \mathrm{~h}$. Luciferase activity was normalized to Renilla luciferase activity and expressed as fold change vs. controls. (F) ATF3 and JunB chromatin immunoprecipitation was performed in exATF3 and exNC cells. As a control, an isotype of anti-ATF3 and anti-JunB monoclonal antibodies was used to measure the background. (G) DNA precipitation was performed in exATF3 and control cells to extract biotinylated DNA fragment (containing an AP-1 site) bound ATF3 and JunB, detected using western blotting. Data are presented as the mean \pm SD $(\mathrm{n}=3)$ and were analyzed using one-tailed Student's t-test. ${ }^{*} \mathrm{P}<0.05,{ }^{* *} \mathrm{P}<0.01,{ }^{* * *} \mathrm{P}<0.001$ vs. the control group unless otherwise specified. ATF3, activating transcriptional factor 3; ns, not significant; $\mathrm{NC}$, negative control; AP-1, activator protein 1; Kd, dissociation constant.

majority of cases, estrogen and progesterone have a significant role in the pathogenesis of $\mathrm{EC}$, the basic mechanism is yet to be fully elucidated. ATF3 has been reported to participate in the carcinogenesis of various types of cancer, such as prostatic 


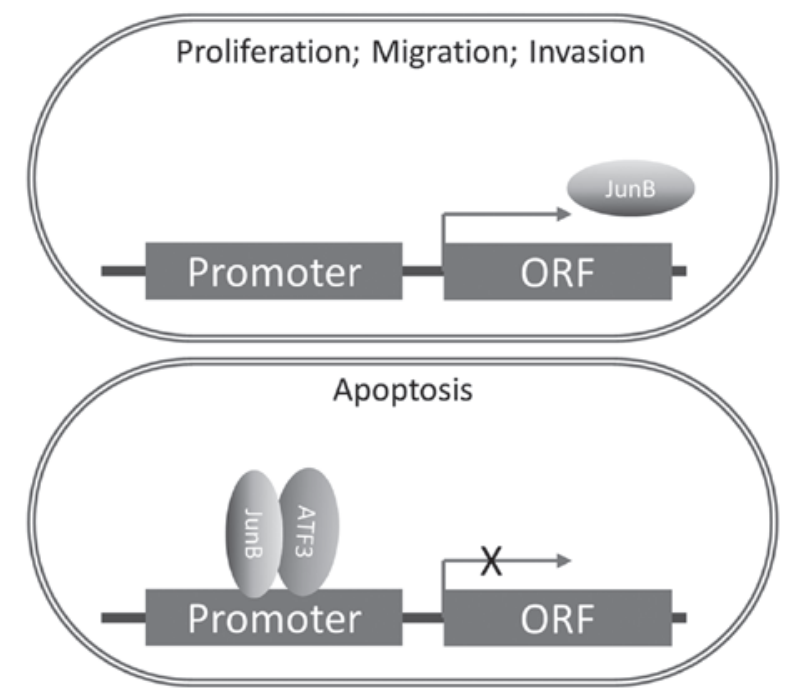

Figure 6. Schematic diagram of the ATF3/JunB pathway in endometrial carcinoma, as a representative regulating model of AP-1 binding by to ATF3/ JunB complex. ATF3/JunB complex binds to the AP-1 site of the promoter of JunB to inhibit the expression of JunB, which mitigates cell proliferation, migration and invasion and facilitates cell apoptosis. $\mathrm{X}$ indicates transcriptional inhibition. ATF3, activating transcriptional factor 3; AP-1, activator protein 1 ; ORF, open reading frame.

cancer (26), but the roles of ATF3 in EC remain unknown. The present results demonstrated that ATF3 inhibited the proliferation, migration and invasion of EC cells, at least in part by interacting with JunB.

JunB is an important transcriptional factor regulating the cell cycle, thus reflecting cell proliferation in ECs $(27,28)$. JunB has been shown to have an oncogenic role and can promote cancer progression, invasion and metastasis in uveal carcinoma (29), multiple myeloma (30), breast cancer (31) and squamous cell carcinoma $(32,33)$. Furthermore, JunB acts as an oncogene and induces abnormal proliferation of previously quiescent cells (34). JunB, as a member of the AP-1 family, is considered to exert its function via AP-1 signaling (35). Various mechanisms underlying the AP-1-mediated regulation of tumor progression, particularly invasion and metastasis, have been reported. For instance, JunB regulates several genes, including MMP2, MMP9 and C-C motif chemokine ligand-2, to enhance tumor invasion and angiogenesis in renal cell carcinomas (36). With AP-1 sites in the promoters, MMPs are considered to be regulated by AP-1, formed by AP-1 family members, including JunB (24,25). Therefore, JunB may be a promising therapeutic target for various cancer types.

In the present study, it was demonstrated that ATF3 was able to impair the function of AP-1 and JunB to regulate MMP by forming a complex with JunB. In addition, ATF3 suppressed the transcription and translation of JunB (Fig. 6). To the best of our knowledge, this is a novel mechanism regarding the regulation of the function of JunB in carcinomas. In addition, the minimum concentration requirements for the interaction between ATF3 and JunB were examined, and it was speculated that the possible reason as to why ATF3 did not bind to JunB in native ECs may be the low concentration of ATF3, which impedes the affinity between ATF3 and JunB.

Similar to JunB, ATF3 is a member of the AP-1 family, but the role of ATF3 in tumors is more complex and its influence on cells is context-dependent (37). ATF3 regulates gene expression in various conditions via binding to the different ATF3/cyclic adenosine monophosphate-responsive element-binding protein cis-regulatory elements (38-40). Moreover, the expression of ATF3 is activated by transforming growth factor- $\beta$ binding to its receptor, resulting in the phosphorylation of SMAD3. The stress signal, acting via p38 kinase, is also able to induce ATF3 expression (41).

ATF3 can inhibit apoptosis induced by stimuli in cardiac myocytes (42), but it also induces apoptosis in tumors (16). Moreover, in varying tumor types, the functions of ATF3 may be different or even the opposite. Under certain circumstances, ATF3 has been shown to promote oncogenesis and migration in skin, breast, prostate and colon cancer (17,43-46). ATF3 expression may be associated with increased metastasis in melanoma and in breast cancer cells $(47,48)$, and knockdown of ATF3 reduces the ability of HT29 colon cancer cells to invade (46), suggesting that ATF3 acts as a cancer promoter. However, previous studies on ATF3 have also revealed a tumor suppressor role in colon, breast, prostate, bladder, glioblastoma and lung cancer by inhibiting cell proliferation and metastasis, and promoting cell death and apoptosis (47-53). Furthermore, a previous study reported that ATF3 may function as a tumor suppressor in Ras-mediated tumorigenesis (54). It has been suggested that the various and context-dependent roles of ATF3 in cancer are due to the complex ATF3-associated protein-protein interaction networks. Thus, ATF3 may be capable of interacting with numerous important and critical proteins to regulate their functions, in addition to its transcriptional regulation (55).

The ATF3/JunB interaction was previously identified to exert an inhibitory effect on human prostate cancer (45). In line with this finding, the present results demonstrated that ATF3 was able to inhibit the progression, invasion and metastasis of ECs via binding to the AP-1 sites in the promoters of various genes, including JunB and MMPs. However, it remains elusive whether ATF3, independent of the ATF3/JunB complex, is able to help degrade MMPs via a proteasome-dependent pathway, as has been reported in esophageal cancer (56). The present findings may explain why ECs lost their transmigration and invasion ability after ATF3 overexpression, as the ratio of MMPs/TIMPs, regulated by ATF3, decrease significantly. Moreover, these results are in line with a previous study, which revealed that ATF3 was able to reduce the ability of human glioblastoma to migrate by regulating MMPs and TIMPs (21).

In our previous study, Y2H mating experiments of ATF3 were performed and $>274$ interactions were identified in human healthy ovary tissues, of which JunB is one of the most positive interacting partners of ATF3 (data not yet published). This finding is consistent with the result of the present study and the earlier studies, which demonstrated that the Fos/Jun and ATF/cAMP response element binding protein families of transcription factors function in dimerization (57), which is mediated by the 'leucine-zipper' motif, and bind to DNA to alter the expression of specific target genes. While the interaction between ATF3 and JunB has been revealed in other tissues or cell types, to the best of our knowledge, the present study was the first to assess this interaction in ECs. The results suggested that the inhibition of ECs by ATF3 may be used as a novel therapeutic strategy for EC. 
In conclusion, analysis of EC tissue samples from 50 cases identified a weak expression of ATF3, but upregulation of JunB expression in EC tissues. It was found that overexpression of ATF3 resulted in downregulation of JunB expression. Further investigation demonstrated that the ATF3/JunB complex bound to the promoter and inhibited the expression of JunB, thus resulting in the remodeling of EC cells and mitigated developments of EC in vitro and in vivo. Therefore, JunB may serve as a potential therapeutic target for EC, and ATF3 as an effective therapeutic tool.

\section{Acknowledgements}

The authors would like to thank Dr Hao Ye (School of Pharmacy, Shanghai Jiao Tong University) for his technical assistance.

\section{Funding}

This work was supported by the National Natural Science Foundation of China (grant nos. 81502233 and 31770922), the Science and Technology Commission of Shanghai Municipality (grant no. 134119a8100) and the Young Scientific Research Project of Shanghai Municipal Health Bureau (grant no. 20134Y176).

\section{Availability of data and materials}

The datasets used or analyzed during the current study are available from the corresponding author upon reasonable request.

\section{Authors' contributions}

FW, JG, HW and JL conducted the experiments and analyzed the results. FW and JG conceived the experiments. FZ and JG supervised the project and interpreted the data. FW, FZ and JG wrote the article. All authors read and approved the final manuscript.

\section{Ethics approval and consent to participate}

The protocol (approval no. 0101N16032) of the present study was approved by the Human Investigation Ethical Committee of Shanghai First People's Hospital Affiliated Shanghai Jiao Tong University (Shanghai, China) and Renji Hospital Affiliated to Shanghai Jiao Tong University School of Medicine (Shanghai, China). All samples were obtained from patients who had provided written informed consent for the use of their tissues for the purposes of research after the operation.

The animal experiment was in accordance with the recommendations in the Guidelines for the Care and Use of Laboratory Animals of China (http://www.nsfc.gov. cn/nsfc/cen/pfzl/pufanew/20110801_02.pdf). The protocol (approval no. 2013020346) was approved by the Committee on the Ethics of Animal Experiments of the School of Pharmacy of Shanghai Jiao Tong University (Shanghai, China).

\section{Patient consent for publication}

Not applicable.

\section{Competing interests}

The authors declare that they have no competing interests.

\section{References}

1. Siegel RL, Miller KD and Jemal A: Cancer statistics, 2019. CA Cancer J Clini 69: 7-34, 2019.

2. Sorosky JI: Endometrial cancer. Obstet Gynecol 120: 383-397, 2012.

3. Salvesen HB, Haldorsen IS and Trovik J: Markers for individualised therapy in endometrial carcinoma. Lancet Oncol 13: e353-e361, 2012.

4. Dedes KJ, Wetterskog D, Ashworth A, Kaye SB and Reis-Filho JS: Emerging therapeutic targets in endometrial cancer. Nature reviews. Clin Oncol 8: 261-271, 2011.

5. Gressel GM, Parkash V and Pal L: Management options and fertility-preserving therapy for premenopausal endometrial hyperplasia and early-stage endometrial cancer. Int J Gynaecol Obstet 131: 234-239, 2015.

6. Brooks RA, Fleming GF, Lastra RR, Lee NK, Moroney JW, Son $\mathrm{CH}$, Tatebe $\mathrm{K}$ and Veneris JL: Current recommendations and recent progress in endometrial cancer. CA Cancer J Clin 69: 258-279, 2019.

7. Wang D, Zheng W, Wang SM, Wang JB, Wei WQ, Liang H, Qiao YL and Boffetta P: Estimation of cancer incidence and mortality attributable to overweight, obesity, and physical inactivity in China. Nutr Cancer 64: 48-56, 2012.

8. Lee YC, Lheureux S and Oza AM: Treatment strategies for endometrial cancer: Current practice and perspective. Curr Opin Obstet Gynecol 29: 47-58, 2017.

9. Bokhman JV: Two pathogenetic types of endometrial carcinoma. Gynecol Oncol 15: 10-17, 1983.

10. Lax SF, Kendall B, Tashiro H, Slebos RJ and Hedrick L: The frequency of $\mathrm{p} 53$, K-ras mutations, and microsatellite instability differs in uterine endometrioid and serous carcinoma: Evidence of distinct molecular genetic pathways. Cancer 88: 814-824, 2000.

11. Norimatsu Y, Ohsaki H, Yanoh K, Kawanishi N and Kobayashi TK: Expression of immunoreactivity of nuclear findings by p53 and cyclin a in endometrial cytology: Comparison with endometrial glandular and stromal breakdown and endometrioid adenocarcinoma grade 1. Diagn Cytopathol 41: 303-307, 2013.

12. Yan C, Lu D, Hai T and Boyd DD: Activating transcription factor 3 , a stress sensor, activates p53 by blocking its ubiquitination. EMBO J 24: 2425-2435, 2005.

13. Wei S, Wang H, Lu C, Malmut S, Zhang J, Ren S, Yu G, Wang W, Tang DD and Yan C: The activating transcription factor 3 protein suppresses the oncogenic function of mutant $\mathrm{p} 53$ proteins. J Biol Chem 289: 8947-8959, 2014.

14. Corrigendum to 'Revised FIGO staging for carcinoma of the cervix uteri' (Int J Gynecol Obstet 145(2019) 129-135). Int J Gynecol Obstet 147: 279-280, 2019.

15. Livak KJ and Schmittgen TD: Analysis of relative gene expression data using real-time quantitative PCR and the 2(-Delta Delta C(T)) method. Methods 25: 402-408, 2001.

16. Song HM, Park GH, Eo HJ and Jeong JB: Naringenin-mediated ATF3 expression contributes to apoptosis in human colon cancer. Biomol Ther (Seoul) 24: 140-146, 2016.

17. Wu ZY, Wei ZM, Sun SJ, Yuan J and Jiao SC: Activating transcription factor 3 promotes colon cancer metastasis. Tumour Biol 35: 8329-8334, 2014.

18. Li X, Zhou X, Li Y, Zu L, Pan H, Liu B, Shen W, Fan Y and Zhou Q: Activating transcription factor 3 promotes malignance of lung cancer cells in vitro. Thorac Cancer 8: 181-191, 2017.

19. Fan TJ, Han LH, Cong RS and Liang J: Caspase family proteases and apoptosis. Acta Biochim Biophys Sin (Shanghai) 37: 719-727, 2005.

20. Inoue M, Uchida Y, Edagawa M, Hirata M, Mitamura J, Miyamoto D, Taketani K, Sekine S, Kawauchi J and Kitajima S: The stress response gene ATF3 is a direct target of the Wnt $/ \beta$-catenin pathway and inhibits the invasion and migration of HCT116 human colorectal cancer cells. PLoS One 13: e0194160, 2018.

21. Guenzle J, Wolf LJ, Garrelfs NW, Goeldner JM, Osterberg N, Schindler CR, Saavedra JE and Weyerbrock A: ATF3 reduces migration capacity by regulation of matrix metalloproteinases via NFkappaB and STAT3 inhibition in glioblastoma. Cell Death Discov 3: 17006, 2017. 
22. Yang HK, Jeong KC, Kim YK and Jung ST: Role of matrix metalloproteinase (MMP) 2 and MMP-9 in soft tissue sarcoma. Clin Orthop Surg 6: 443-454, 2014.

23. Jujo T, Sakao S, Tsukahara M, Kantake M, Maruoka M, Tanabe N, Masuda $\mathrm{M}$ and Tatsumi K: The role of matrix metalloproteinase in the intimal sarcoma-like cells derived from endarterectomized tissues from a chronic thromboembolic pulmonary hypertension patient. PLoS One 9: e87489, 2014.

24. Clark IM, Swingler TE, Sampieri CL and Edwards DR: The regulation of matrix metalloproteinases and their inhibitors. Int J Biochem Cell Biol 40: 1362-1378, 2008.

25. Page-McCaw A, Ewald AJ and Werb Z: Matrix metalloproteinases and the regulation of tissue remodelling. Nature reviews. Mol Cell Biol 8: 221-233, 2007.

26. Wang Z, Kim J, Teng Y, Ding HF, Zhang J, Hai T, Cowell JK and Yan C: Loss of ATF3 promotes hormone-induced prostate carcinogenesis and the emergence of CK5(+)CK8(+) epithelial cells. Oncogene 35: 3555-3564, 2016.

27. Papoudou-Bai A, Goussia A, Batistatou A, Stefanou D, Malamou-Mitsi V and Kanavaros P: The expression levels of JunB, JunD and p-c-Jun are positively correlated with tumor cell proliferation in diffuse large B-cell lymphomas. Leuk Lymphoma 57: 143-150, 2016.

28. Bamberger AM, Milde-Langosch K, Rossing E, Goemann C and Loning T: Expression pattern of the AP-1 family in endometrial cancer: Correlations with cell cycle regulators. J Cancer Res Clin Oncol 127: 545-550, 2001.

29. Gong C, Shen J, Fang Z, Qiao L, Feng R, Lin X and Li S: Abnormally expressed JunB transactivated by IL-6/STAT3 signaling promotes uveal melanoma aggressiveness via epithelial-mesenchymal transition. Biosci Rep 38: BSR20180532, 2018.

30. Fan F, Bashari MH, Morelli E, Tonon G, Malvestiti S, Vallet $S$, Jarahian M, Seckinger A, Hose D, Bakiri L, et al: The AP-1 transcription factor JunB is essential for multiple myeloma cell proliferation and drug resistance in the bone marrow microenvironment. Leukemia 31: 1570-1581, 2017.

31. Sundqvist A, Morikawa M, Ren J, Vasilaki E, Kawasaki N, Kobayashi M, Koinuma D, Aburatani H, Miyazono K, Heldin $\mathrm{CH}$, et al: JUNB governs a feed-forward network of TGF $\beta$ signaling that aggravates breast cancer invasion. Nucleic Acids Res 46: 1180-1195, 2018.

32. Sun Y, Wang J, Pan S, Yang T, Sun X, Wang Y, Shi X, Zhao X, Guo J and Zhang X: LINC00657 played oncogenic roles in esophageal squamous cell carcinoma by targeting miR-615-3p and JunB. Biomed Pharmacother 108: 316-324, 2018.

33. Hyakusoku H, Sano D, Takahashi H, Hatano T, Isono Y, Shimada S, Ito Y, Myers JN and Oridate N: JunB promotes cell invasion, migration and distant metastasis of head and neck squamous cell carcinoma. J Exp Clin Cancer Res 35: 6, 2016.

34. Pei H, Guo Z, Wang Z, Dai Y, Zheng L, Zhu L, Zhang J, Hu W, Nie J, Mao W, et al: RAC2 promotes abnormal proliferation of quiescent cells by enhanced JUNB expression via the MAL-SRF pathway. Cell Cycle 17: 1115-1123, 2018.

35. Rao GN, Katki KA, Madamanchi NR, Wu Y and Birrer MJ: JunB forms the majority of the AP-1 complex and is a target for redox regulation by receptor tyrosine kinase and $\mathrm{G}$ protein-coupled receptor agonists in smooth muscle cells. J Biol Chem 274: 6003-6010, 1999.

36. Kanno T, Kamba T, Yamasaki T, Shibasaki N, Saito R, Terada N, Toda Y, Mikami Y, Inoue T, Kanematsu A, et al: JunB promotes cell invasion and angiogenesis in VHL-defective renal cell carcinoma. Oncogene 31: 3098-3110, 2012.

37. Rohini M, Haritha Menon A and Selvamurugan N: Role of activating transcription factor 3 and its interacting proteins under physiological and pathological conditions. Int $\mathrm{J}$ Biol Macromol 120: 310-317, 2018.

38. Chen BP, Liang G, Whelan J and Hai T: ATF3 and ATF3 delta Zip. Transcriptional repression versus activation by alternatively spliced isoforms. J Biol Chem 269: 15819-15826, 1994.

39. Hashimoto Y, Zhang C, Kawauchi J, Imoto I, Adachi MT, Inazawa J, Amagasa T, Hai T and Kitajima S: An alternatively spliced isoform of transcriptional repressor ATF3 and its induction by stress stimuli. Nucleic Acids Res 30: 2398-2406, 2002.

40. Cai Y, Zhang C, Nawa T, Aso T, Tanaka M, Oshiro S, Ichijo H and Kitajima S: Homocysteine-responsive ATF3 gene expression in human vascular endothelial cells: Activation of c-Jun $\mathrm{NH}(2)$-terminal kinase and promoter response element. Blood 96: 2140-2148, 2000.
41. Li Y,LiZ,Zhang C, Li P, Wu Y, Wang C, Bond Lau W, Ma XL and Du J: Cardiac Fibroblast-specific activating transcription factor 3 protects against heart failure by suppressing MAP2K3-p38 signaling. Circulation 135: 2041-2057, 2017.

42. Nobori K, Ito H, Tamamori-Adachi M, Adachi S, Ono Y, Kawauchi J, Kitajima S, Marumo F and Isobe M: ATF3 inhibits doxorubicin-induced apoptosis in cardiac myocytes: A novel cardioprotective role of ATF3. J Mol Cell Cardiol 34: 1387-1397, 2002.

43. Wu X, Nguyen BC, Dziunycz P, Chang S, Brooks Y, Lefort K, Hofbauer GF and Dotto GP: Opposing roles for calcineurin and ATF3 in squamous skin cancer. Nature 465: 368-372, 2010.

44. Yin X, Wolford CC, Chang YS, McConoughey SJ, Ramsey SA, Aderem A and Hai T: ATF3, an adaptive-response gene, enhances TGF $\{$ beta\} signaling and cancer-initiating cell features in breast cancer cells. J Cell Sci 123: 3558-3565, 2010.

45. Liu W, Iiizumi-Gairani M, Okuda H, Kobayashi A, Watabe M, Pai SK, Pandey PR, Xing F, Fukuda K, Modur V, et al: KAI1 gene is engaged in NDRG1 gene-mediated metastasis suppression through the ATF3-NFkappaB complex in human prostate cancer. J Biol Chem 286: 18949-18959, 2011.

46. Ishiguro $\mathrm{T}$, Nagawa $\mathrm{H}$, Naito $\mathrm{M}$ and Tsuruo $\mathrm{T}$ : Inhibitory effect of ATF3 antisense oligonucleotide on ectopic growth of HT29 human colon cancer cells. Jpn J Cancer Res 91: 833-836, 2000.

47. Ishiguro $T$, Nakajima $M$, Naito $M$, Muto $T$ and Tsuruo $T$ : Identification of genes differentially expressed in B16 murine melanoma sublines with different metastatic potentials. Cancer Res 56: 875-879, 1996.

48. Iyengar P, Combs TP, Shah SJ, Gouon-Evans V, Pollard JW, Albanese C, Flanagan L, Tenniswood MP, Guha C, Lisanti MP, et al: Adipocyte-secreted factors synergistically promote mammary tumorigenesis through induction of anti-apoptotic transcriptional programs and proto-oncogene stabilization. Oncogene 22: 6408-6423, 2003.

49. Gargiulo G, Cesaroni M, Serresi M, de Vries N, Hulsman D, Bruggeman SW, Lancini $C$ and van Lohuizen M: In vivo RNAi screen for BMI1 targets identifies TGF-beta/BMP-ER stress pathways as key regulators of neural- and malignant glioma-stem cell homeostasis. Cancer Cell 23: 660-676, 2013.

50. Yuan X, Yu L, Li J, Xie G, Rong T, Zhang L, Chen J, Meng Q, Irving AT, Wang D, et al: ATF3 suppresses metastasis of bladder cancer by regulating gelsolin-mediated remodeling of the actin cytoskeleton. Cancer Res 73: 3625-3637, 2013.

51. HacklC,Lang SA, Moser C,Mori A,Fichtner-Feigl S, HellerbrandC, Dietmeier W, Schlitt HJ, Geissler EK and Stoeltzing O: Activating transcription factor-3 (ATF3) functions as a tumor suppressor in colon cancer and is up-regulated upon heat-shock protein 90 (Hsp90) inhibition. BMC Cancer 10: 668, 2010.

52. Jan YH, Tsai HY, Yang CJ, Huang MS, Yang YF, Lai TC, Lee CH, Jeng YM, Huang CY, Su JL, et al: Adenylate kinase-4 is a marker of poor clinical outcomes that promotes metastasis of lung cancer by downregulating the transcription factor ATF3. Cancer Res 72: 5119-5129, 2012.

53. Bandyopadhyay S, Wang Y, Zhan R, Pai SK, Watabe M, Iiizumi M, Furuta E, Mohinta S, Liu W, Hirota S, et al: The tumor metastasis suppressor gene Drg-1 down-regulates the expression of activating transcription factor 3 in prostate cancer. Cancer Res 66: 11983-11990, 2006.

54. Lu D, Wolfgang CD and Hai T: Activating transcription factor 3, a stress-inducible gene, suppresses Ras-stimulated tumorigenesis. J Biol Chem 281: 10473-10481, 2006.

55. Buganim Y, Madar S, Rais Y, Pomeraniec L, Harel E, Solomon H, Kalo E, Goldstein I, Brosh R, Haimov O, et al: Transcriptional activity of ATF3 in the stromal compartment of tumors promotes cancer progression. Carcinogenesis 32: 1749-1757, 2011

56. Xie JJ, Xie YM, Chen B, Pan F, Guo JC, Zhao Q, Shen JH, Wu ZY, Wu JY, Xu LY and Li EM: ATF3 functions as a novel tumor suppressor with prognostic significance in esophageal squamous cell carcinoma. Oncotarget 5: 8569-8582, 2014.

57. Gazon H, Barbeau B, Mesnard JM and Peloponese JM Jr: Hijacking of the AP-1 signaling pathway during development of ATL. Front Microbiol 8: 2686, 2017.

This work is licensed under a Creative Commons Attribution-NonCommercial-NoDerivatives 4.0 International (CC BY-NC-ND 4.0) License. 